\title{
Simulating the Structural Response of a Preloaded Bolted Joint
}

\author{
Norman F. Knight, Jr. ${ }^{1}$ \\ General Dynamics - Advanced Information Systems, Chantilly, VA 20151 \\ Dawn R. Phillips ${ }^{2}$ \\ Lockheed Martin Mission Services, Hampton, VA 23681 \\ and \\ Ivatury S. Raju \\ NASA Langley Research Center. Hampton, VA 23681
}

\begin{abstract}
The present paper describes the structural analyses performed on a preloaded boltedjoint configuration. The joint modeled was comprised of two L-shaped structures connected together using a single bolt. Each $L$-shaped structure involved a vertical flat segment (or shell wall) welded to a horizontal segment (or flange). Parametric studies were performed using elasto-plastic, large-deformation nonlinear finite element analyses to determine the influence of several factors on the bolted-joint response. The factors considered included bolt preload, washer-surface-bearing size, edge boundary conditions, joint segment length, and loading history. Joint response is reported in terms of displacements, gap opening, and surface strains. Most of the factors studied were determined to have minimal effect on the bolted-joint response; however, the washer-bearing-surface size affected the response significantly.
\end{abstract}

\section{Introduction}

Preloaded bolted-joint connections are common place in engineering design of shell segments (e.g., see Ref. 14). Preloading the bolts is generally done to reduce cyclic stresses, maintain joint closure, or increase overall stiffness [4]. One configuration is the assembly of cylindrical shells with end flanges. These shell segments can be assembled together through a bolted-joint connection along adjacent flanges as illustrated in Figures 1 and 2 . In the design of these connections [1-4], the structural response of the preloaded bolted joint and its sensitivity to parameter variations need to be understood. This paper presents detailed stress analyses of a preloaded bolted joint and presents the influence of various parameters on the bolted-joint performance. Such results can be used as pretest predictions and, when available, subsequently correlated with test data.

The outline of the present paper is as follows. First, the bolted-joint configuration is described, and an estimate of bolt stress for the design load is discussed. Then, the analysis tools and computational environment are described, and the modeling assumptions are stated. Finally, numerical results and discussion are presented

\section{Joint Configuration}

The preloaded bolted-joint configuration is illustrated in Figures 1 and 2. It involved two flat segments with 15 inches of 0.5 -inch-thick shell wall material and a 6-inch-wide, 1-inch-thick flange welded on one edge to the shell wall. The 3.77-inch-wide specimen is similar to a $2^{\circ}$ slice in the vicinity of a single $7 / 8$-inch-diameter bolt in a large-diameter cylindrical shell. The preload force in the bolt often is not known precisely; however, a preload torque between 300-600 ft-lb was estimated.

\footnotetext{
${ }^{1}$ Chief Engineer, Structural Mechanics. Associate Fellow AIAA, Fellow ASME.

${ }^{2}$ Aerospace Engineer. Member AIAA.

${ }^{3}$ NASA Technical Fellow for Structures, NASA Engineering and Safety Center. Fellow AIAA, Member ASME. 
The material for the bolted joint was assumed to be a high-strength steel with a yield stress of $41 \mathrm{ksi}$. Since elasto-plastic analyses were anticipated, the analyses required the material data in the form of true stress as a function of the plastic strain. ${ }^{4}$ The room-temperature stress-strain curve for high-strength steel is shown in Figure 3. The material for the bolts and washers was assumed to be a high-strength steel with a yield stress of $105 \mathrm{ksi}$. In these analyses, the bolts, nuts, and washers were assumed to respond in a linear elastic manner and were not explicitly modeled in any of the analyses.

\section{Bolt Stress Estimate}

An estimate of the bolt stress is based on a simple strength of materials approach for the bolt and assumes the full utilization of bolt material before failure (i.e., when the stress across the entire bolt cross-sectional area reaches the bolt yield stress). In these analyses, it is assumed that a design tensile axial running load on a cylindrical shell (see Figure 4) is $\widetilde{N}_{x}=1,600 \mathrm{lb} / \mathrm{in}$., which translates into a total axial load of 1.1 million pounds for a shell with approximately a 210 -inch diameter. Then, assuming a $2^{\circ}$ bolt spacing around a shell circumference and using a factor of safety of 1.4, the average axial force carried per bolt is $8,450 \mathrm{lb}$ for each of the 180 bolts. The stress in a bolt due to this mechanical loading is the average bolt axial force divided by the bolt cross-sectional area ( 0.6 in. ${ }^{2}$ for the bolt diameter $d_{\text {bolt }}$ taken as $0.875 \mathrm{in}$.) giving a value of $14 \mathrm{ksi}$.

The bolt preload assumptions include a specified preload torque $T$ and a nut factor $k .^{5}$ The preload torque is related to the preload axial force $F$ by [5]:

$$
T=k F d_{b o l t}
$$

A nominal preload torque of $400 \mathrm{ft}-\mathrm{lb}$ and a nut factor of 0.15 result in a bolt preload axial force of $36,500 \mathrm{lb}$. This force gives an initial stress in the bolt due to preload of $61 \mathrm{ksi}$. Different combinations of preload torque and nut factor values give the same preload force for a given bolt diameter as indicated in Figure 5. For example, a preload axial force of 36,500 lb can be obtained, as shown in Figure 5, using a preload torque of $267 \mathrm{ft}-\mathrm{lb}$ and a nut factor of 0.10 , a preload torque of $400 \mathrm{ft}-\mathrm{lb}$ and a nut factor of 0.15 , or a preload torque of $533 \mathrm{ft}-\mathrm{lb}$ and a nut factor of 0.20 .

Hence, the total bolt stress is estimated as the sum of the stress due to the mechanical loads and the stress due to the preload force. Thus, the total bolt stress is estimated to be $75 \mathrm{ksi}$ (i.e., $14 \mathrm{ksi}+61 \mathrm{ksi}$ ). This value is well below the yield stress of the bolt material, $105 \mathrm{ksi}$. Incipient bolt yield force is defined as the preload force equivalent to complete bolt cross-sectional yielding (i.e., bolt yield stress multiplied by the bolt cross-sectional area) and is equal to $63,000 \mathrm{lb}^{6}$

\section{Modeling Assumptions}

Several fundamental assumptions are common in the development of models used in the stress analyses. Each assumption is described next. First, the bolts, nuts, and washers were not explicitly represented in the finite element models, but rather their influence was simulated. The bolts were represented as one-dimensional linear elastic beams. The washers were represented as sets of kinematic coupling constraints that extended from the bolt centerline to a specified distance on the outer flanges to simulate the bearing load. Kinematic coupling constrained the nodes associated with the washer-bearing surface to the translation and rotation of a node on the bolt. Hence, this type of constraint can represent the effects of bolt bending on the local stress state in the flange near the washer. The washer-bearing-surface modeling assumptions are illustrated in Figure 6, where the extent of the kinematic coupling constraints extends a distance $\beta$ radially outward from the edge of the bolt hole.

Second, the finite element models were developed to accommodate different material properties in regions of the analysis model as indicated in Figure 7. The shell wall is welded to the flange using a through-the-thickness butt weld followed by a fillet weld along the shell-wall-to-flange intersection on the back side of the L-shaped structure.

\footnotetext{
${ }^{4}$ For the uniaxial case, the nominal stress is the applied load divided by the initial cross sectional area, and the nominal strain is the change in length divided by the original length.

${ }^{5}$ A nut factor is a factor used to account for friction in the threads of the bolt and nut [4].

${ }^{6}$ In cases where the bolt preload force is unknown, a percentage of the incipient bolt yield force is assumed as the bolt preload force, for example, $65 \%$ of bolt yield gives a preload force of 41,000 lb.
} 
The weld regions are shown in yellow in Figure 7. Because of the welding process, the material properties in regions near the weld, known as the heat-affected zone (HAZ), could be affected. The regions shown in magenta and light green in Figure 7 are heat-affected zones. In the present analyses, all regions, including the weld and HAZ, used the parent material properties.

Third, the computational effort for these finite element models was reduced by incorporating two different modeling regions as indicated in Figure 1. Away from the local joint region, a two-dimensional shell finite element model, incorporating the ABAQUS S4 standard shell element, was used to represent the structure. While a shell element has more nodal degrees of freedom than a solid element, no explicit through-the-thickness modeling is required because of the kinematic assumptions employed by shell elements. The use of two-dimensional shell elements for the far-field response readily accommodates the specification of shell running loads or end displacements. Near the joint region, three-dimensional solid finite element modeling was employed. The threedimensional finite element modeling incorporated the ABAQUS C3D8I 8-node solid element, which includes incompatible modes as element shape functions for improved bending response. At the interface of the twodimensional and three-dimensional regions, multi-point constraints were defined through a shell-to-solid connection constraint for connecting a two-dimensional shell finite element model to a three-dimensional solid finite element model. Along the shell-to-solid interface, the nodes on the edge of the shell element region are coincident with nodes on the solid element region at the middle surface of the shell wall.

\section{Numerical Results and Discussion}

Engineering analysis of the bolted-joint configuration required the use of several different computer-aided engineering analysis tools including those for representing the geometry, those for generating the finite element models, those for performing the structural analyses, and those for post-processing the computed results. Analyses were performed to study system response, to identify modeling issues for accurate simulation of the bolted-joint structure, and to provide pre-test predictions, if required. The joint response is characterized using several measures as a function of the applied end displacement: bolt axial load, reaction force at the fixed end, flange separation (or gap opening), lateral displacement of the joint, and surface strains.

All analyses were performed using ABAQUS/Standard. ${ }^{7}$ The analysis process involved two basic stages. The first stage was to increase the bolt preload axial force from zero to a specified value and monitor local deformation and stress behavior. The second stage, starting from the preload bolt joint state, was to apply a tensile end displacement incrementally. These analyses were nonlinear due to the explicit contact modeling between the adjacent flange faces and to represent any geometric or material nonlinearities.

\section{A. Effect of Mesh Refinement}

Two different finite element models were used in the analysis of the preloaded bolted joint to assess the effect of finite element mesh refinement. First, a coarse finite element mesh, shown in Figure 8, was developed and assessed. The coarse mesh was designed to represent all significant structural behavior up to approximately twice the design load and also to be amenable to multiple bolt structural configurations while keeping the solution times reasonable. Then, a second more refined model, shown in Figure 9, was developed, and the predicted response compared to the results obtained using the coarse model. The refined mesh was designed for use in detailed analysis studies of the bolted joint when loaded to failure.

A 1/4-inch washer-bearing-surface assumption and a $400 \mathrm{ft}$-lb preload torque in the bolt were assumed for both finite element models. The $400 \mathrm{ft}-\mathrm{lb}$ bolt preload torque was converted into a 36,500 lb bolt preload axial force using Eq. 1 with an assumed nut factor of 0.15 for steel on steel. An applied uniform extensional end displacement $\Delta$ was imposed along the upper edge and reacted through the fixed boundary along the lower edge as illustrated in Figure 1 .

The reaction force as a function of end displacement for the coarse and refined meshes is shown in Figure 10. Both results show good correlation up to approximately $20,000 \mathrm{lb}$ - more than twice the design load $(8,450 \mathrm{lb})$. The predicted response for the coarse mesh was somewhat stiffer than the predicted response obtained using the refined

\footnotetext{
${ }^{7} \mathrm{ABAQUS} /$ Standard is a registered trademark of ABAQUS, Inc.
} 
mesh for load levels above 20,000 lb. Therefore, the finite element model with the refined mesh shown in Figure 9 is used in all subsequent simulations and is referred to as the baseline analysis model.

\section{B. Baseline Analysis Case Results}

The baseline analysis case is defined as the refined finite element model shown in Figure 9 with a $1 / 4$-inch washer-bearing-surface assumption and a $400 \mathrm{ft}-\mathrm{lb}$ preload torque in the bolt. For this preload torque and a 0.15 nut factor, the preload axial force is $36,500 \mathrm{lb}$.

The structural response of the preloaded bolted joint is shown in Figure 11 for the bolt load as a function of the applied end displacement. For the baseline analysis case, the bolt load remains at the preload level $(36,500 \mathrm{lb})$ until the joint begins to separate. Then the end displacement increases until an applied end displacement value of 0.046 inches is reached, which corresponds to when the bolt load reaches the value associated with incipient yield of the bolt (i.e., 63,000 lb). Using this value of the end displacement at incipient bolt yield and the reaction force variation as a function of applied end displacement shown in Figure 12, the applied load for bolt failure is estimated as 30,000 $\mathrm{lb}$ for the baseline analysis assumptions.

The flange separation (or gap opening) is shown in Figure 13 in terms of the reaction force. Below the design load of $8,450 \mathrm{lb}$, minimal flange separation (or gap opening) is observed. As the end displacement increases further, the gap opening also increases in a nonlinear manner, and the gap opening shown in Figure 13 reaches nearly 0.04 inches at an applied load of 30,000 lb, which is the estimated bolt failure load.

The surface strains from the front and back faces as a function of the reaction load are shown in Figure 14. The strains are from a location in the center of the specimen width and one inch above the flange surface. The back face is defined as the side of the specimen with the flanges and bolt. The front face is defined as the side opposite the bolt side. The average strain value represents the nominal membrane strain. The design load $(8,450 \mathrm{lb})$ and the incipient bolt yield load (failure load of 30,000 lb) are indicated on the figure. At the design load, the surface strain level is very small at these locations on the specimen. These strain results also indicate significant bending response in the joint as the reaction load increases. The predicted peak reaction force is $38,500 \mathrm{lb}$ for an end displacement of 0.10 inches. This force is higher than the value estimated for incipient bold yielding $(30,000 \mathrm{lb})$ indicating that the washer-bearing-surface size in the simulation should be reduced.

The lateral displacement of the joint is shown in Figure 15 as a function of the reaction force. The lateral displacement is measured along the front face at the joint interface and is uniform across the joint width. Positive values indicate the joint is displaced in the direction normal to the back face, while negative values indicate the joint is displaced in the direction normal to the front face. Nonzero values are an indication of the eccentricity in the load path through the bolted joint. These results indicate the bolted joint displaces outward (in the direction of the front face) as the end displacement increases.

The distributions of the axial strain $\varepsilon_{22}$ and the von Mises stress $\sigma_{v m}$ for three different load levels are shown in Figure 16 wherein the range of the contour levels is fixed. The contours are shown on the deformed configurations in which the deformations are magnified ten times. Results for 8,450 lb are shown in Figure 16a and indicate low axial strain and von Mises stress levels. Most of the higher stress values are due to bolt/washer bearing on the flange under the preload conditions. At 30,000 lb as shown in Figure 16b, the strain levels are still relatively low, while stress levels in the vicinity of the bolt approach the yield value. High stresses are also noted at the top of the fillet weld on the back-face surface (bolt side) of the specimen. At 38,300 lb as shown in Figure 16c, high axial strains have developed, and widespread yielding of the joint material is predicted.

These results indicate that the basic structural response of a preloaded bolted joint can be readily simulated. The approach is to first analyze the bolt preload condition and then impose the external mechanical loads. Here, the external loading was an applied uniform end displacement that was incrementally increased. A nonlinear iterative solution procedure was applied until convergence was attained for each value of end displacement. The NewtonRaphson incremental-iterative solution procedure continued until convergence could not be obtained due to widespread material yielding. Parametric studies are performed next to determine which factors have more influence on the prediction of the joint structural response. 


\section{Effect of Bolt Preload}

The first modeling assumption considered was the bolt preload torque. In the finite element analysis model, the preload axial force, as determined using Eq. 1, was actually specified rather than the preload torque. However, in a typical bolted joint, the preload torque is measured using a torque wrench.

The structural response of the joint is indicated in Figure 17 in terms of the bolt load as a function of applied end displacement for different preload torque values but assuming a nut factor of 0.15 for all cases. The long edges were free, and the washer-bearing-surface size $\beta$ equaled $1 / 4$-inch. Increasing the preload torque decreased the end displacement that caused incipient bolt yield. However, the influence on the reaction force was minimal as indicated in Figure 18.

\section{Effect of Washer-Bearing-Surface Modeling}

The second modeling assumption considered was the washer-bearing-surface size as illustrated in Figure 6 . The bearing surface is the area near the washer that bears against the flange and holds the joint together. The size of the washer-bearing surface is measured radially outward from the edge of the bolt hole in the flange. In these studies, the washer-bearing-surface size $\beta$ was varied from the nut diameter to somewhat larger than the washer outer diameter (indicated by the "green blocks" in the lower left of the diagram in Figure 2). The long edges were free, and the bolt preload force was $36,500 \mathrm{lb}$.

As the value of $\beta$ increased, for a given end displacement, the bolt load increased as shown in Figure 19 and the reaction force increased as shown in Figure 20. The response of the preloaded bolted joint exhibited a significant sensitivity to different washer-bearing-surface size assumptions. The washer-bearing-surface size has a significant effect on the preloaded bolted-joint response.

\section{E. Effect of Edge Boundary Conditions}

The third modeling assumption considered was the boundary conditions on the long edges of the preloaded bolted joint. Within the joint configuration, these edges were free. However, to assess the relationship between this bolted-joint configuration and a series of bolts along a wider segment, symmetry boundary conditions were applied to the long edges. The bolt preload force was $36,500 \mathrm{lb}$, and different values of the washer-bearing-surface size were evaluated. These results were then compared to the results obtained when the long edges were free.

The influence of the long-edge boundary conditions on the bolt load as a function of end displacement is shown in Figure 21. The influence of the long-edge boundary conditions on the reaction load as a function of end displacement is shown in Figure 22. The solid lines represent the free condition, while the dashed lines represent the symmetry condition. The results imply that the boundary condition along the long edges of the bolted joint (either free or symmetric) have minimal effect on the structural response of the preloaded bolted joint.

\section{F. Effect of Joint Length}

The fourth modeling assumption considered was the length of the preloaded bolted joint (i.e., overall joint length minus twice the grip length). The overall length of the bolted joint was 30 inches. However during testing, a portion of both ends would be covered by mechanical grips to hold the joint in a test machine. In a tensile test of such a bolted joint, the length of the end grips should not have an influence on the local joint response provided the grips are not too close to the region of interest.

Three different grip lengths $\mathrm{L}_{\text {grip }}$ were considered: 0,3 , and 6 inches. The long edges were free, a bolt preload force of 36,500 lb was specified, and a 1/4-inch washer-bearing-surface was assumed. The influence of specimen length on the reaction force as a function of end displacement is shown in Figure 23. While some stiffening of the structural response for increased grip length was noted, the effect was considered minor. The effect on the local von Mises stress distribution is shown in Figure 24 for an applied end displacement of 0.02 inches. As the grip length increased, the stress level near the shell wall to flange intersection did not appear to change significantly.

\section{G. Effect of Loading and Unloading}

A loading and unloading simulation of the preloaded bolted joint was performed. The load was increased incrementally to nearly four times the design load and then the structure was unloaded. The analysis models were 
based on the refined finite element mesh with the long edges free, a bolt preload force of 36,500 lb, and a 1/8-inch washer-bearing-surface size assumption - a value smaller than the value used in the baseline analysis case.

Results for flange separation (or gap opening) are shown in Figure 25 as a function of the reaction force. These results indicate some permanent gap opening of nearly 0.050 inches in the joint after the external load is removed. However, at the design load, an elastic response is predicted.

Surface strain response is given in Figure 26 for a washer-bearing-surface size of $1 / 8$ inch. These surface strains were taken at the center of the specimen width and one inch above the flange. Again, the permanent deformation of the joint when subjected to high axial loading is evident. The peak reaction force for this case is $32,000 \mathrm{lb}$ for an end displacement of 0.10 inches. This value is near the value estimated for incipient bold yield $(30,000 \mathrm{lb})$ indicating that the washer-bearing-surface size assumption is consistent with the basic bolt stress estimate approach presented earlier in the present paper. The influence of the washer-bearing-surface size assumption is evident by comparing Figure 14 for $\beta=1 / 4$ inch and Figure 26 for $\beta=1 / 8$ inch.

\section{Concluding Remarks}

The present paper describes structural analyses of a bolted-joint configuration performed to define basic modeling and analysis requirements and to identify parameters that have significant effect on the response. These analyses were elasto-plastic, large-deformation nonlinear finite element analyses and were performed using the ABAQUS/Standard finite element code. Different parametric studies were performed, and by far, the most significant parameter affecting the bolted-joint response was the washer-bearing-surface size. The results of these parametric studies provide insight to guide subsequent modeling and simulation of bolted segmented shells. Some of the uncertainties in simulating the structural response of these structures can be mitigated by calibrating these analysis results with test results.

\section{References}

1. Shigley, J. E. and Mischke, C. R., Mechanical Engineering Design, Fifth Edition, McGraw-Hill, Inc., New York, 1989.

2. Bickford, J. H., An Introduction to the Design and Behavior of Bolted Joints, Marcel Dekker, Inc., New York, 1990.

3. Krutz, G. W., Schueller, J. K., and Claar, P. W., III, Machine Design for Mobile and Industrial Applications, Society of Automotive Engineers, Inc., Warrendale, PA, 1994.

4. Chambers, J. A., Preloaded Joint Analysis Methodology for Space Flight Systems, NASA TM-106943, December 1995. 


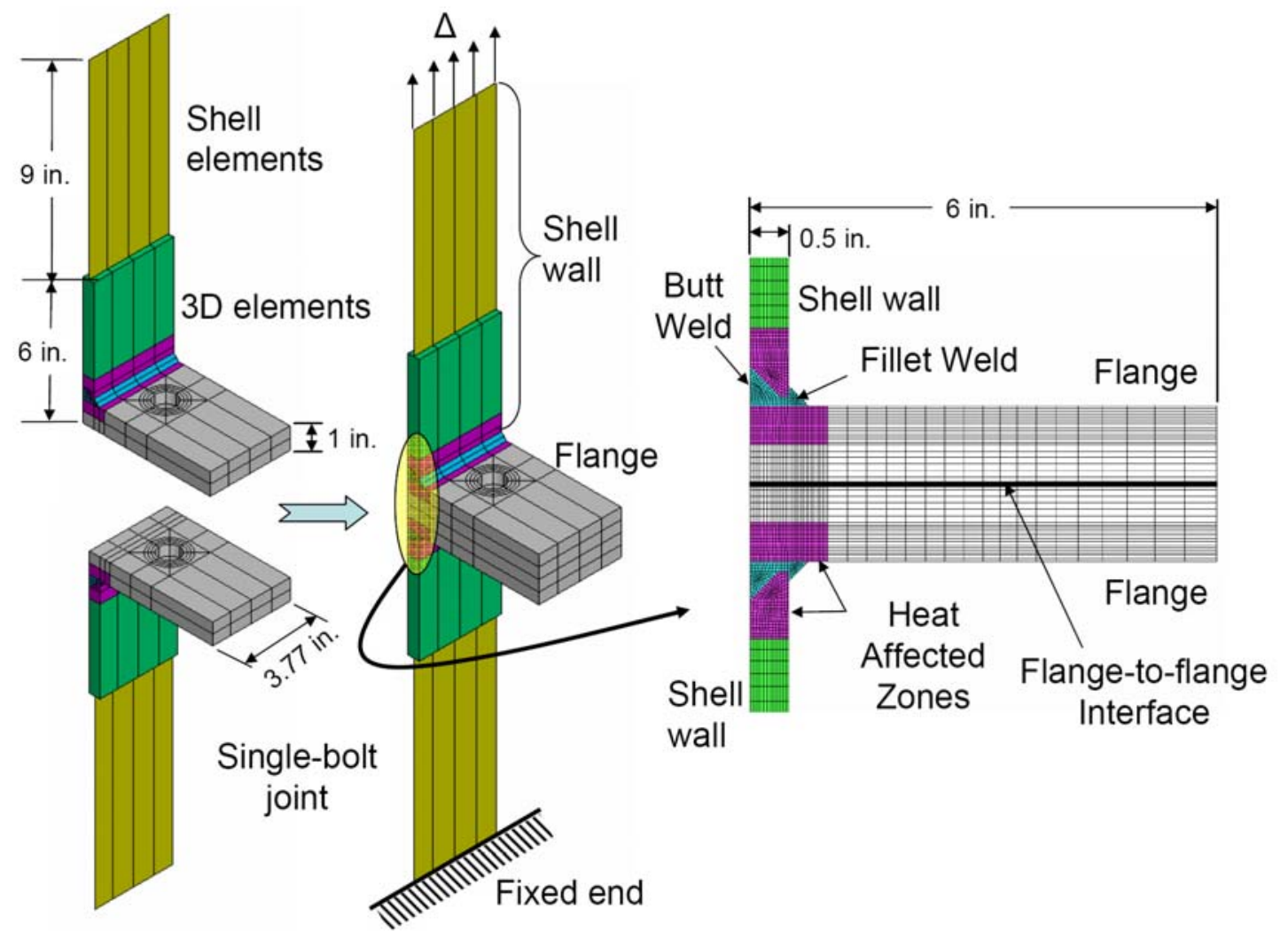

Figure 1. Bolted-joint configuration and nomenclature.

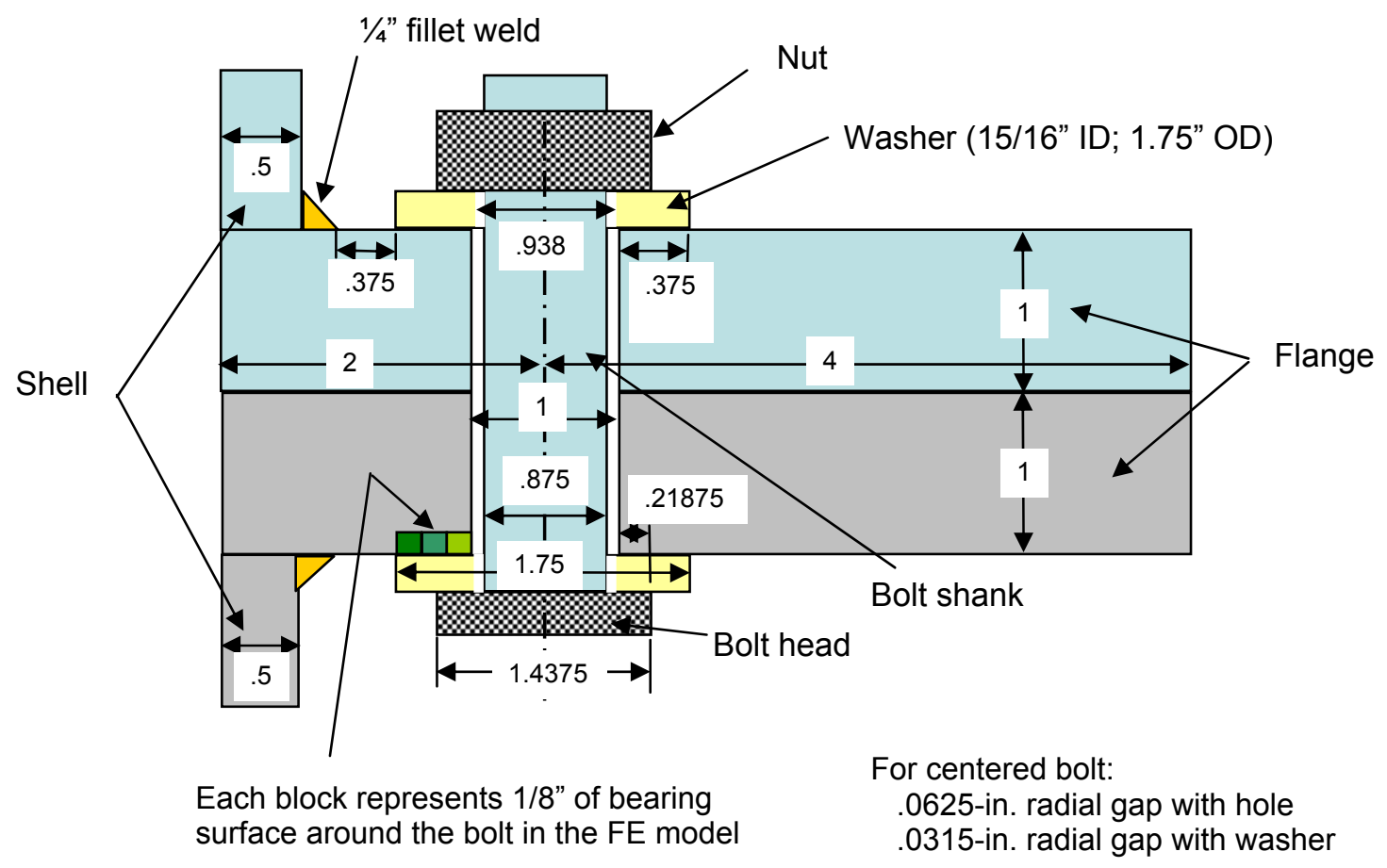

Figure 2. Representative joint and bolt dimensions - all dimensions are inches; not drawn to scale. 


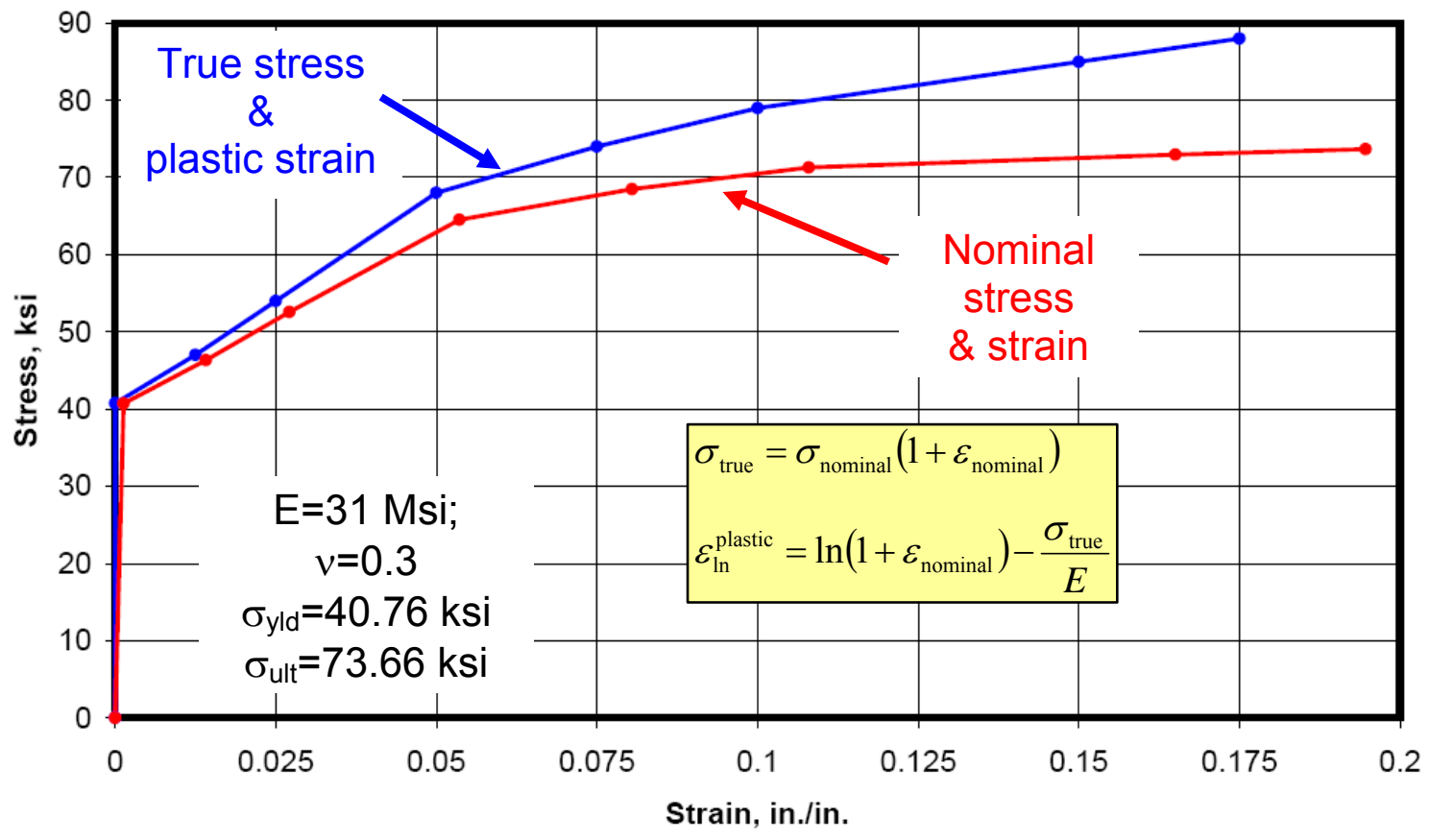

Figure 3. Room-temperature stress-strain curve for a high-strength steel.

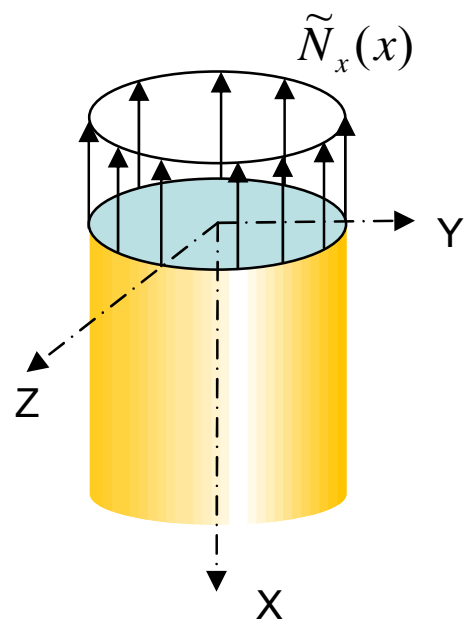

Figure 4. Representative running in-plane axial shell loading. 


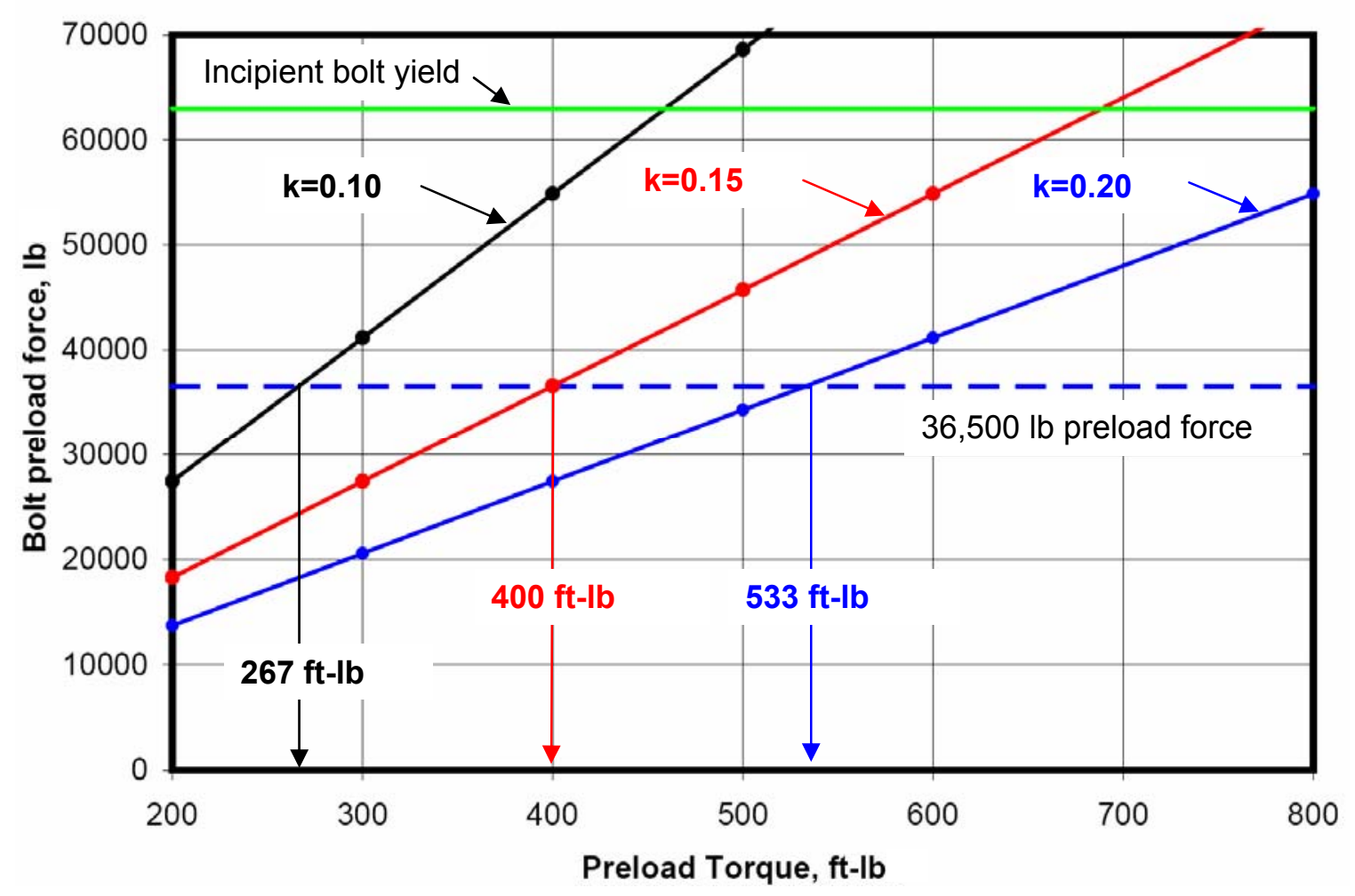

Figure 5. Effect of bolt preload torque and nut factor on bolt preload force.

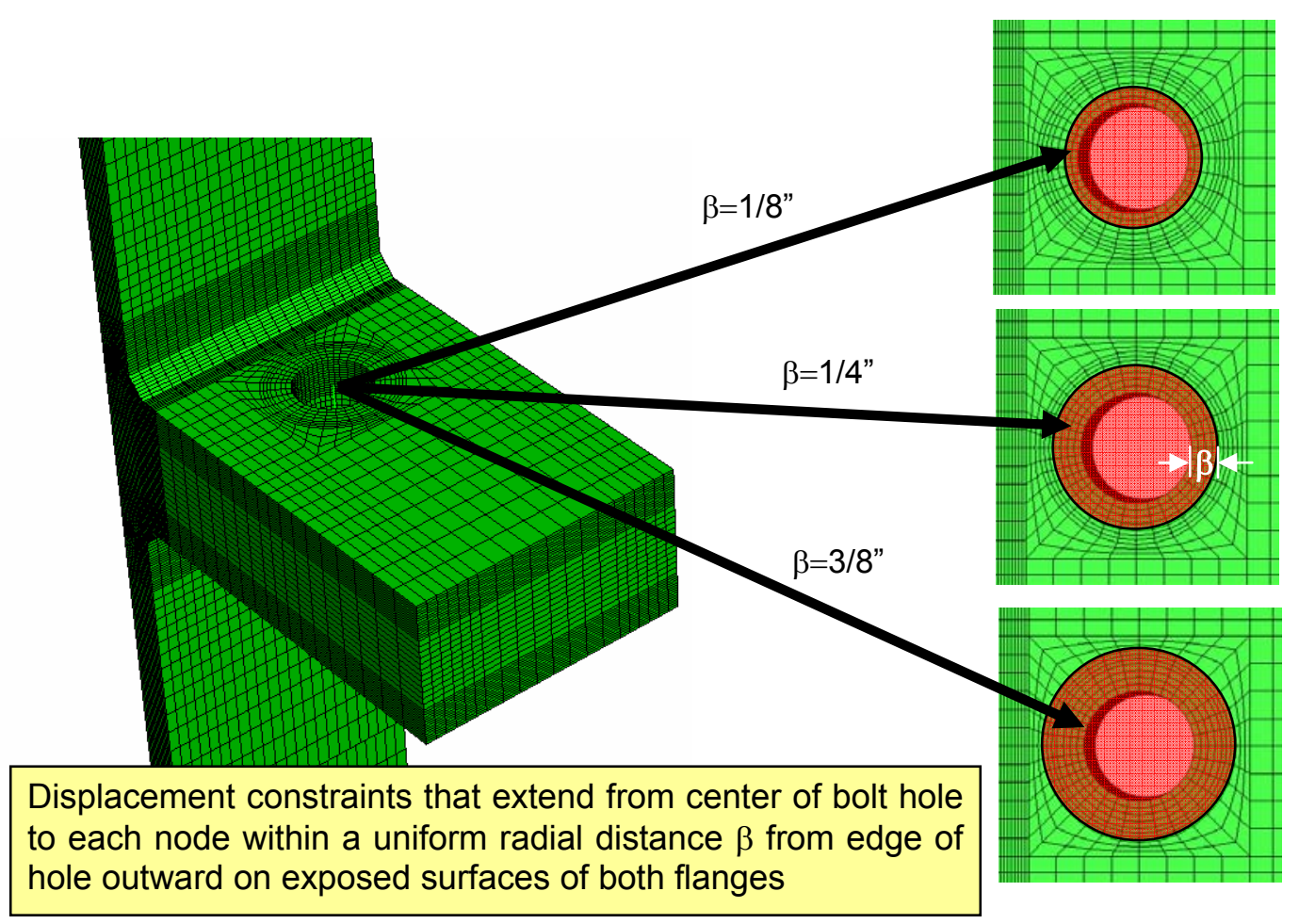

Figure 6. Washer-bearing-surface modeling assumptions. 


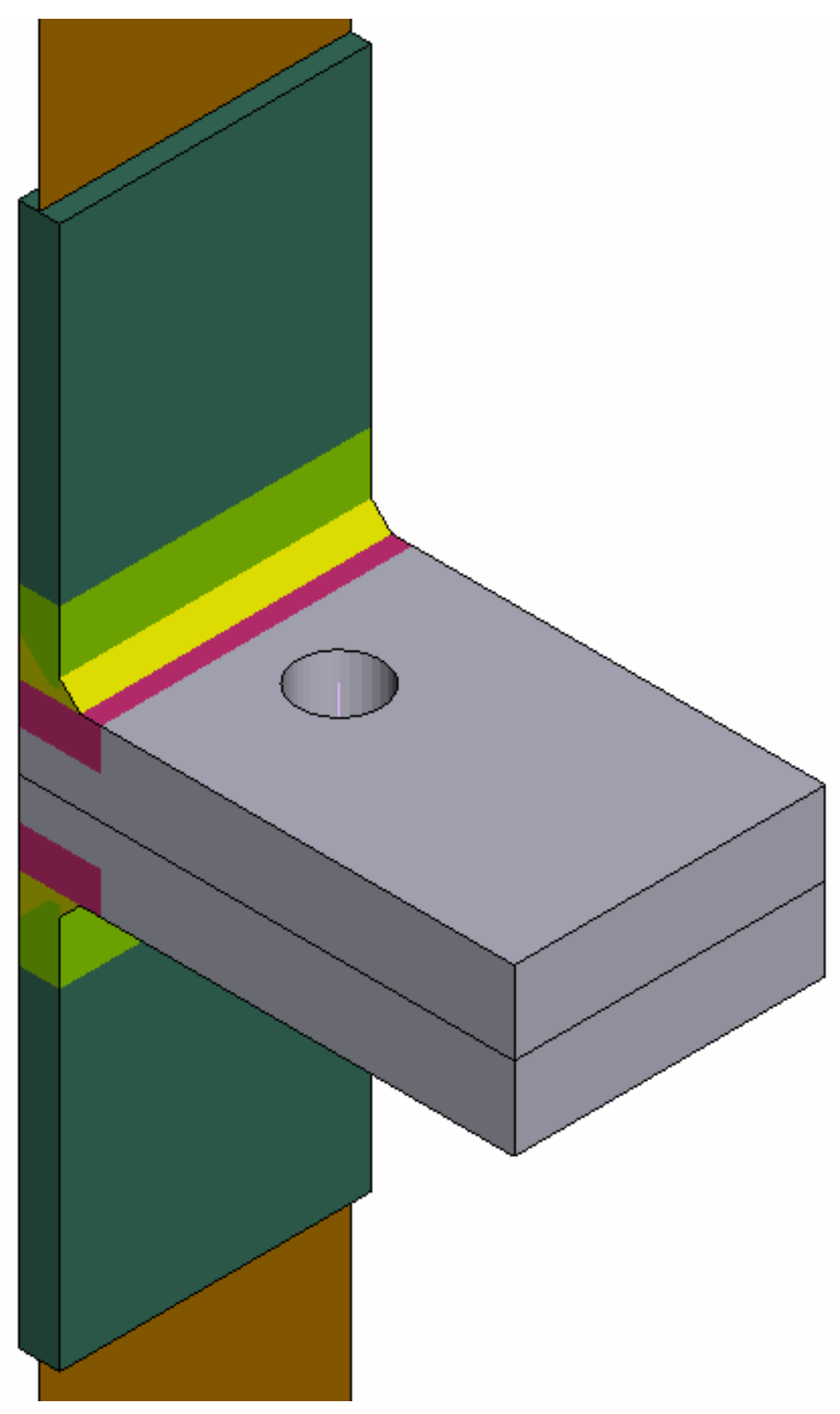

Figure 7. Illustration of regions within the analysis models potentially having different material properties assigned (gray, dark green, and tan regions are parent material; magenta and light green regions are heat-affected zones; yellow region is the weld). 


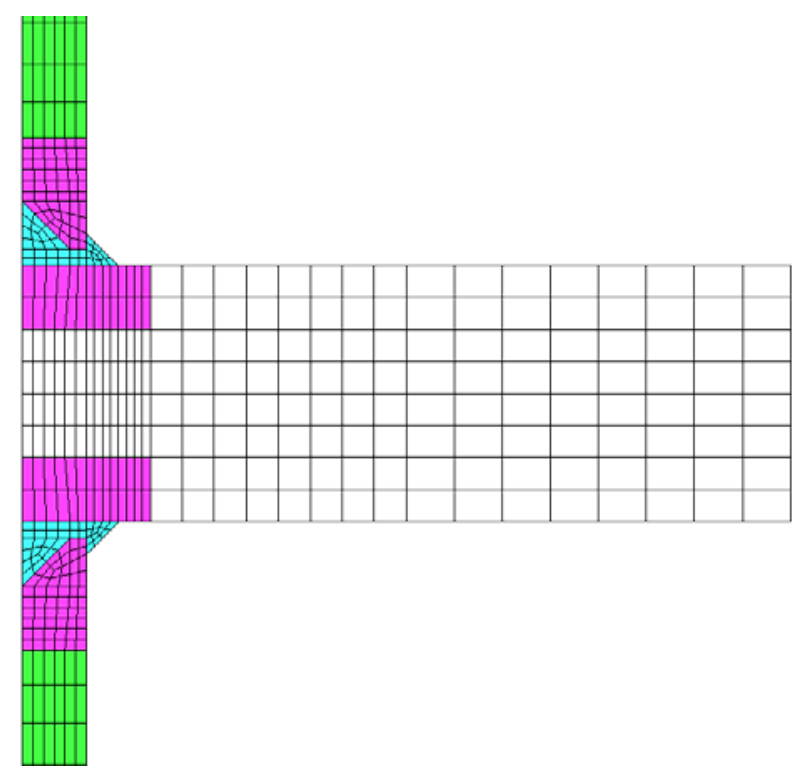

Figure 8. Coarse finite element model of the bolted joint.

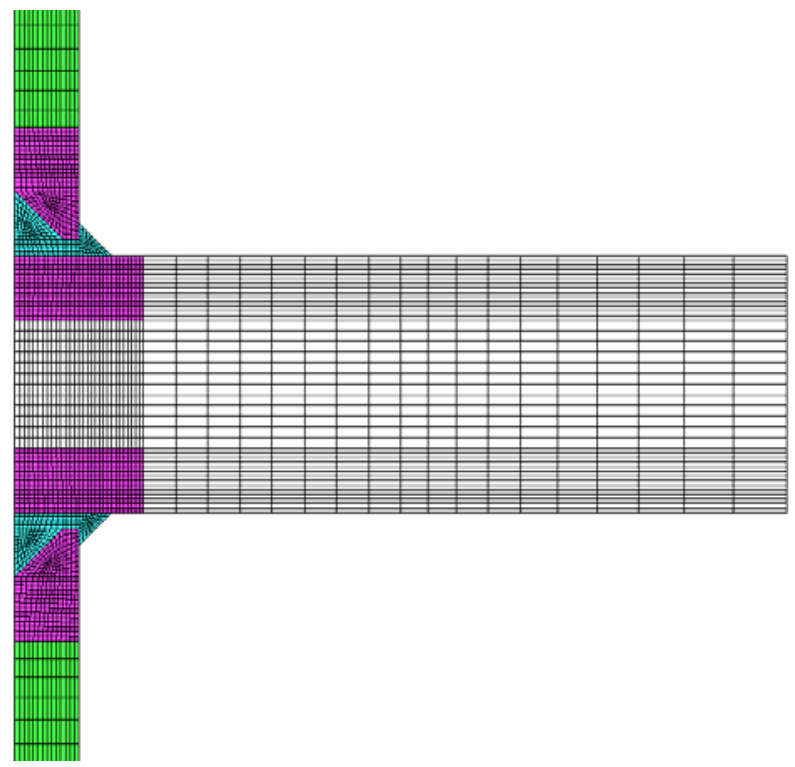

Figure 9. Refined finite element model of the bolted joint. 


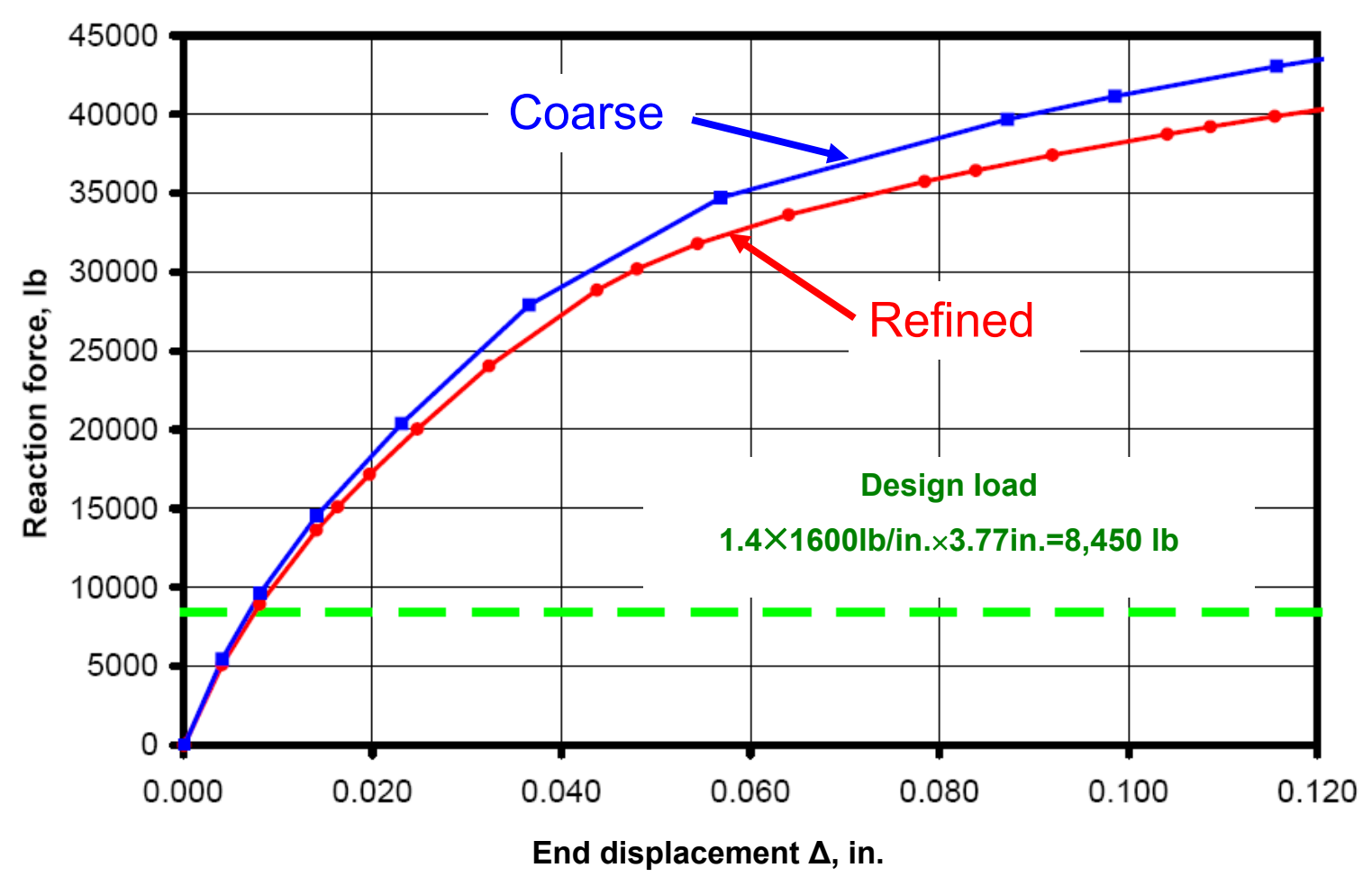

Figure 10. Effect of mesh refinement on bolted-joint structural response.

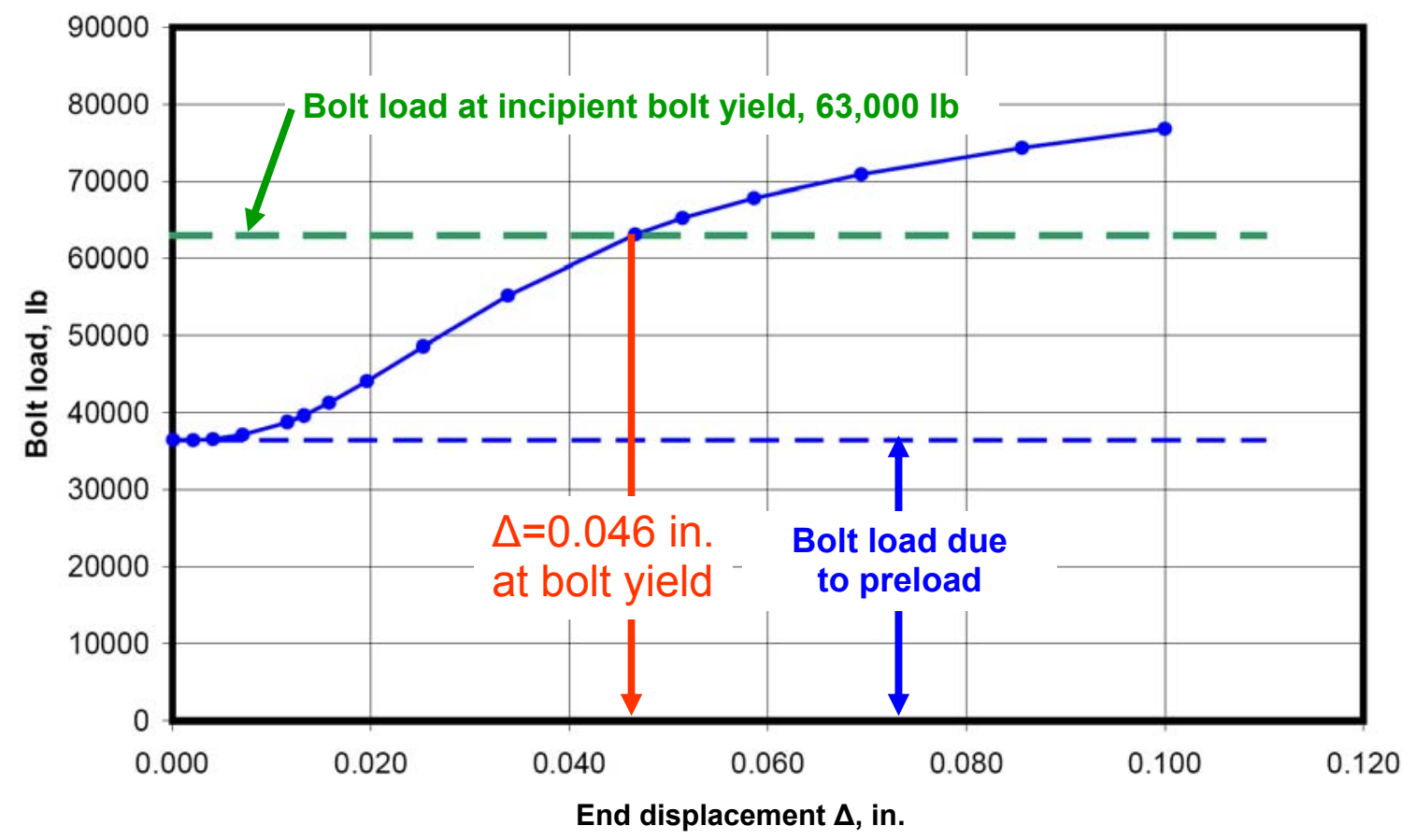

Figure 11. Bolt load as a function of applied end displacement for the baseline analysis case. 


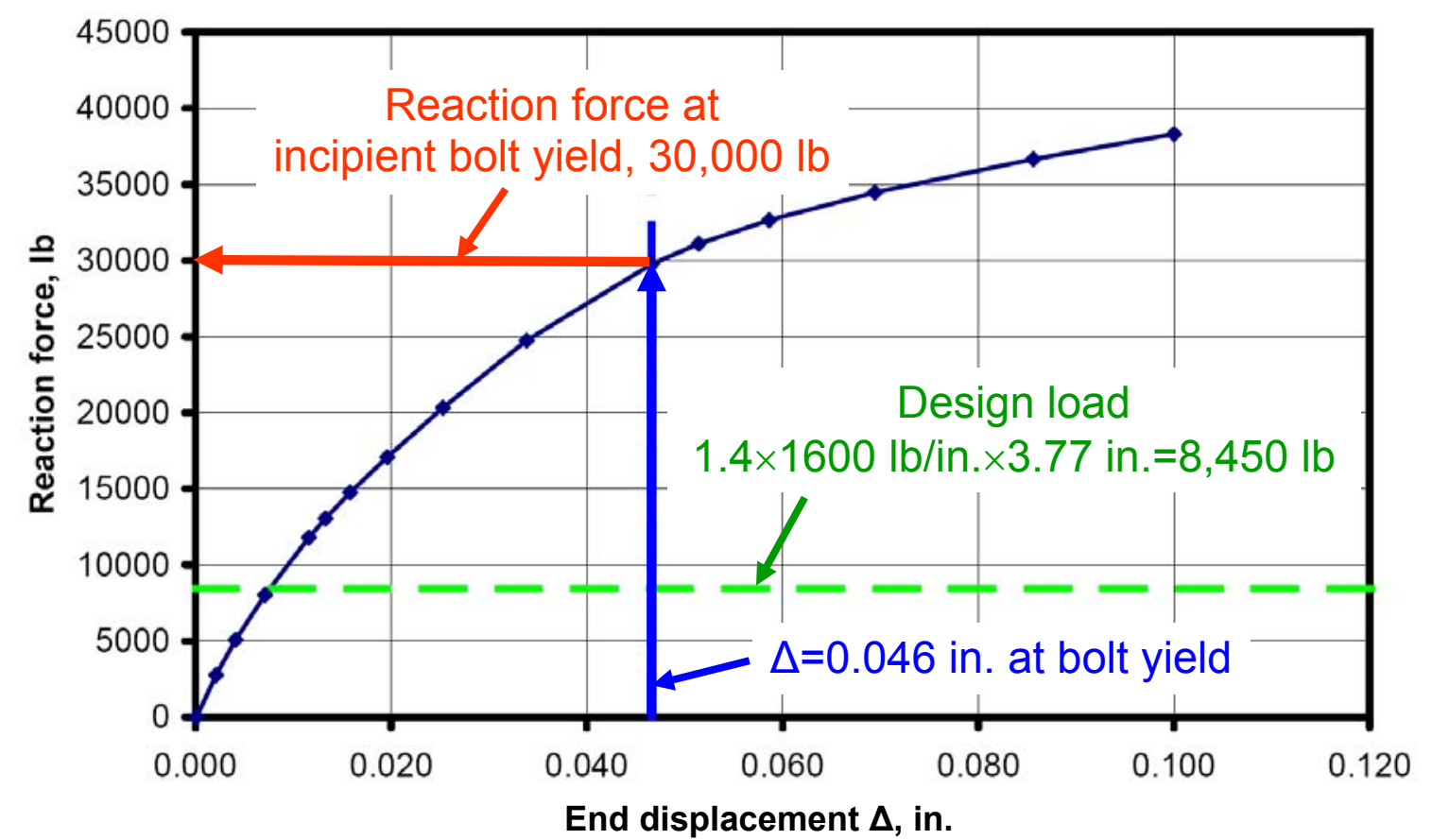

Figure 12. Reaction force as a function of applied end displacement for the baseline analysis case.

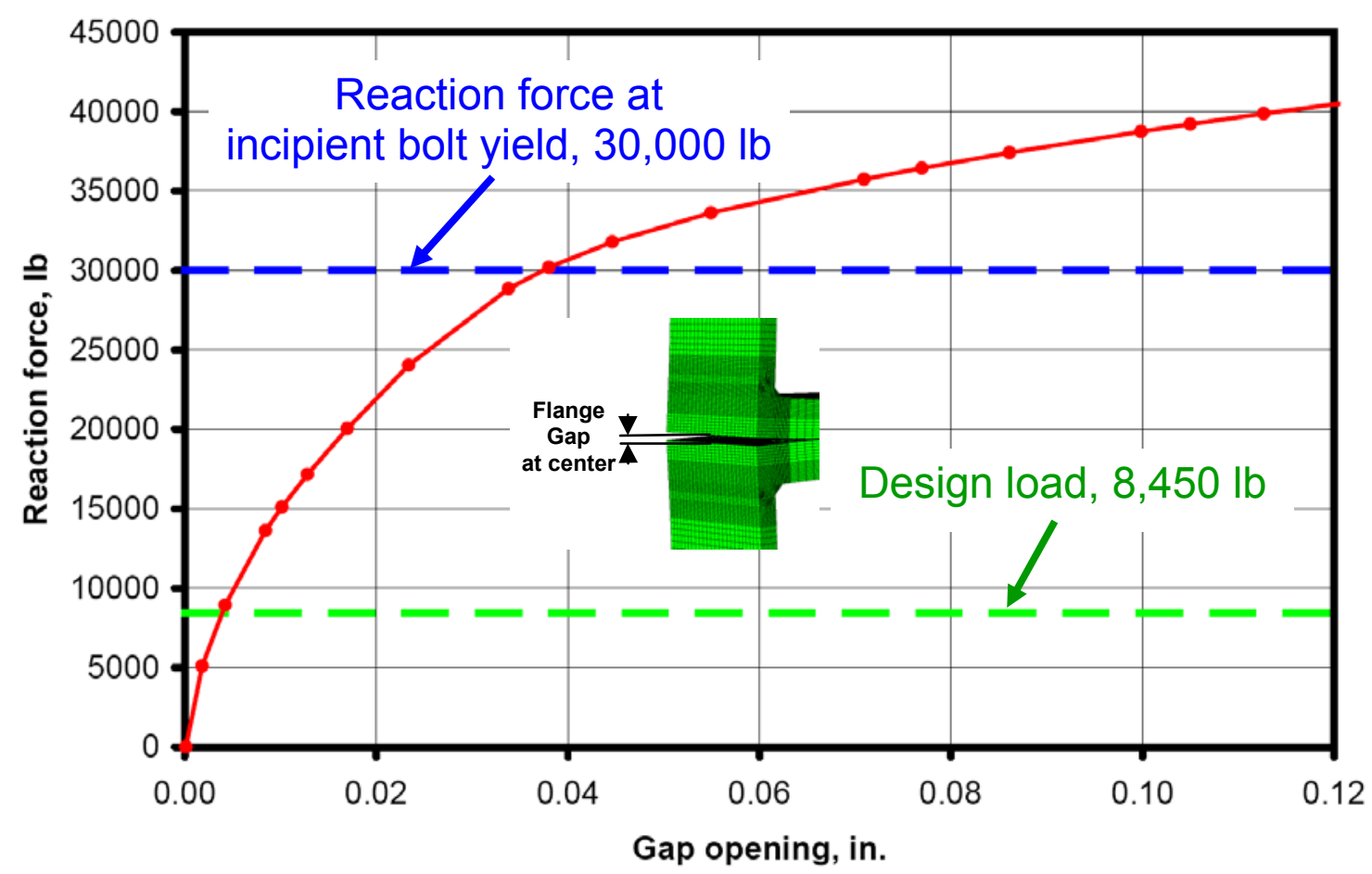

Figure 13. Reaction force as a function of gap opening (or flange gap) for the baseline analysis case. 


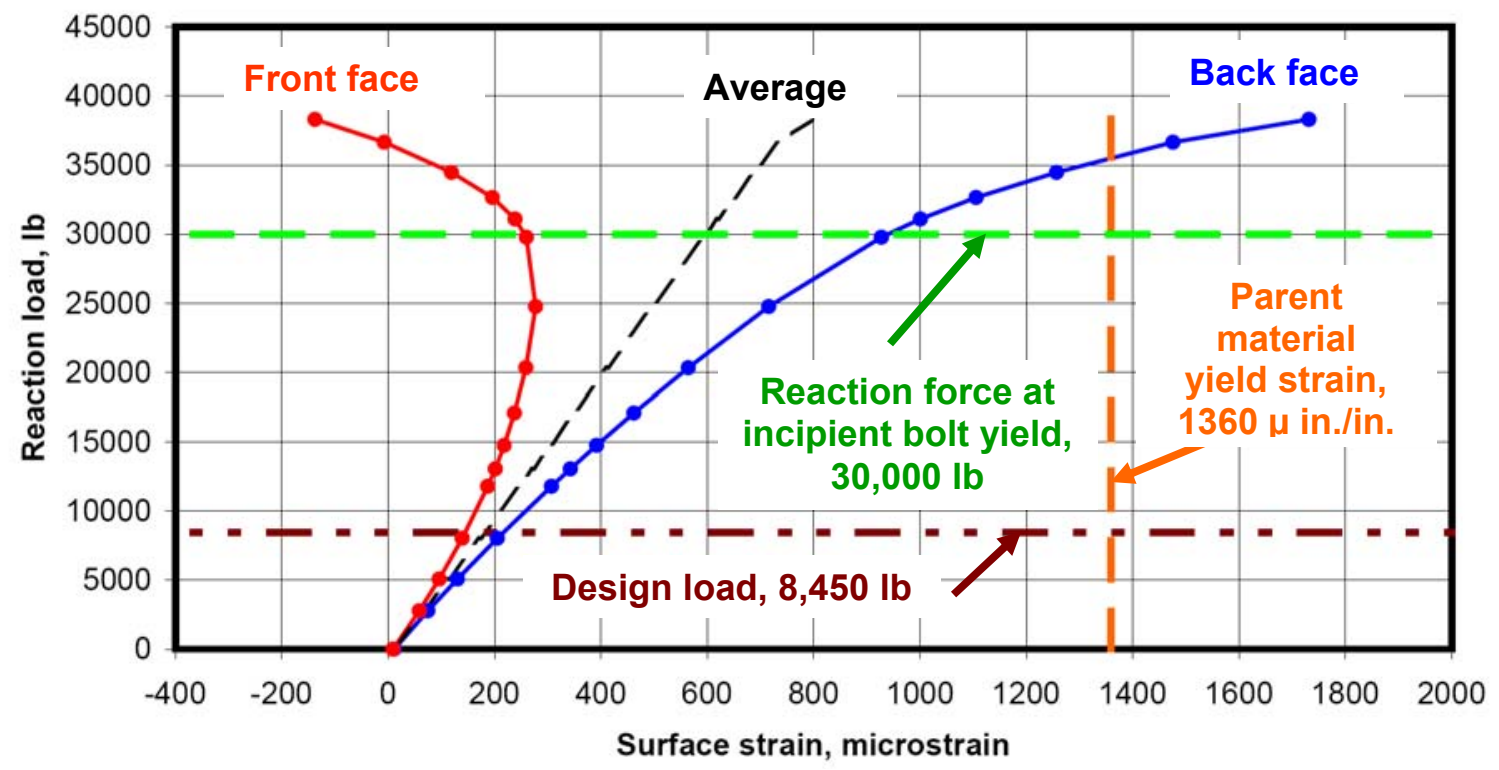

Figure 14. Reaction force as a function of surface strains for the baseline analysis case.

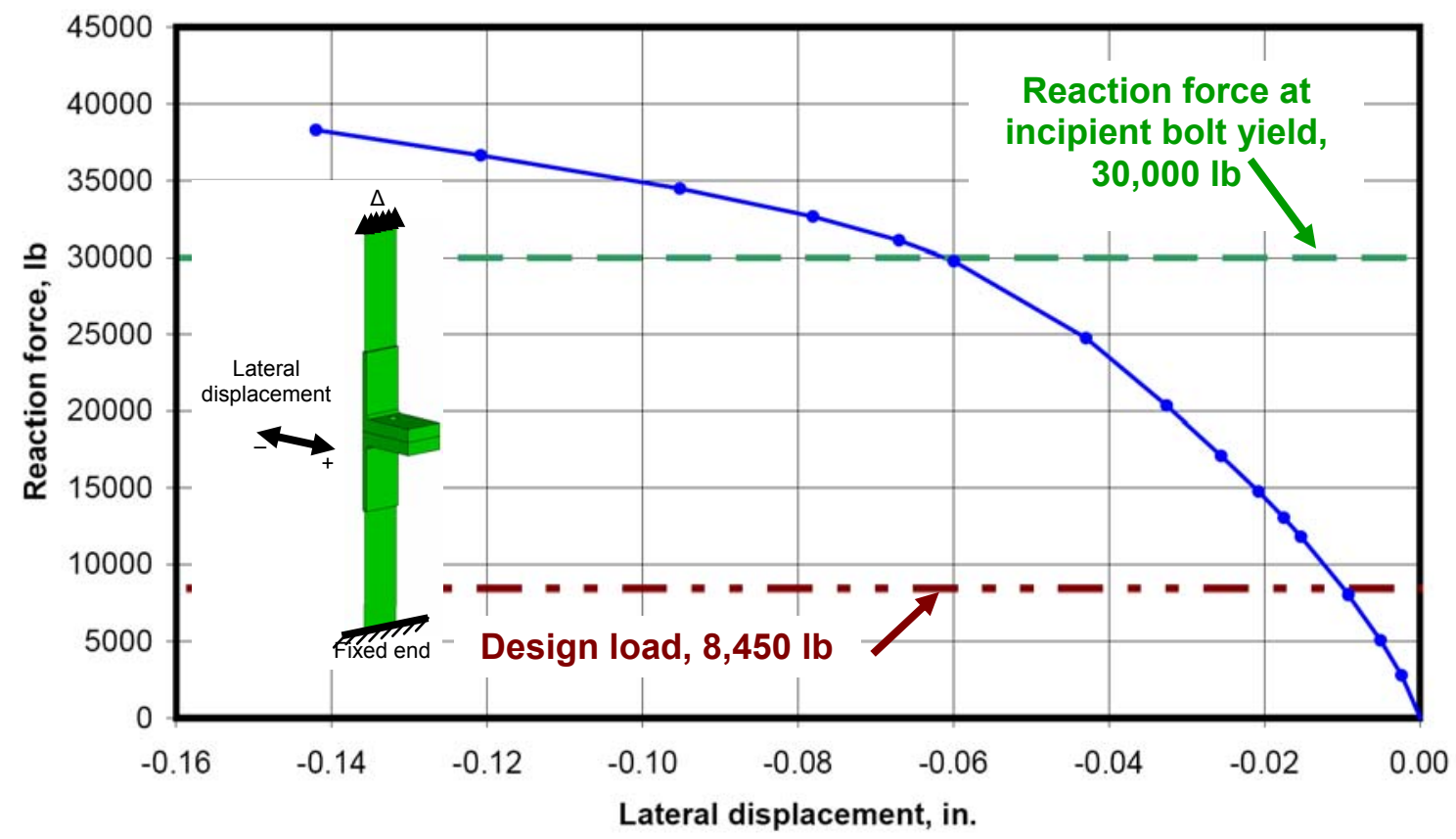

Figure 15. Reaction force as a function of front face lateral displacement for the baseline analysis case. 

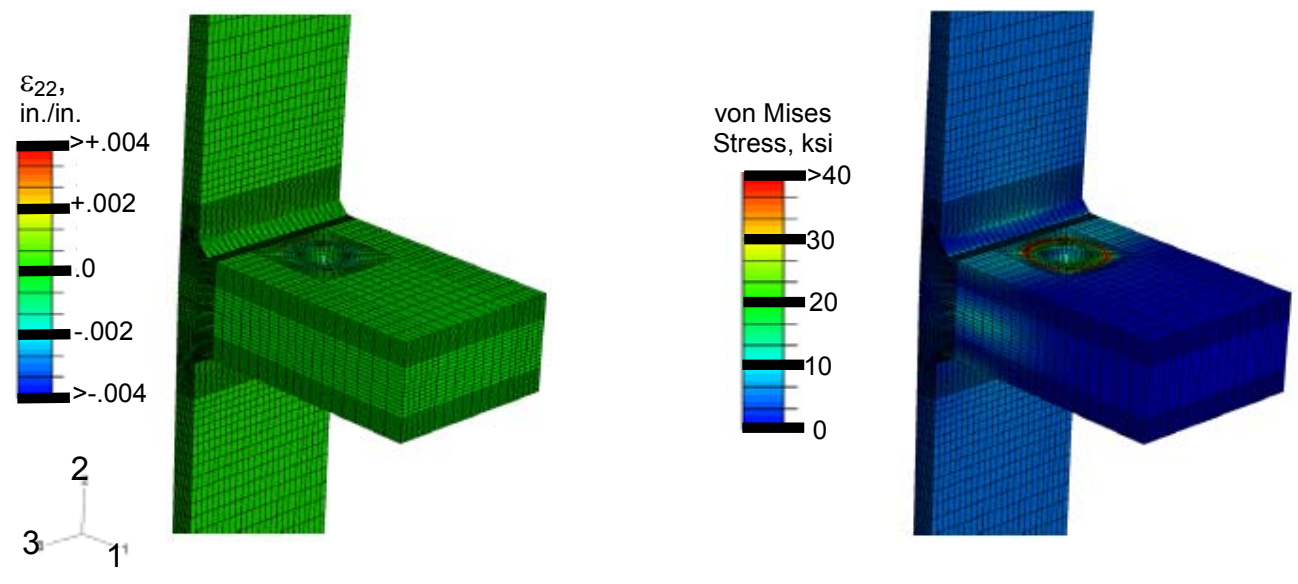

(a) At 8,450 lb (design load).
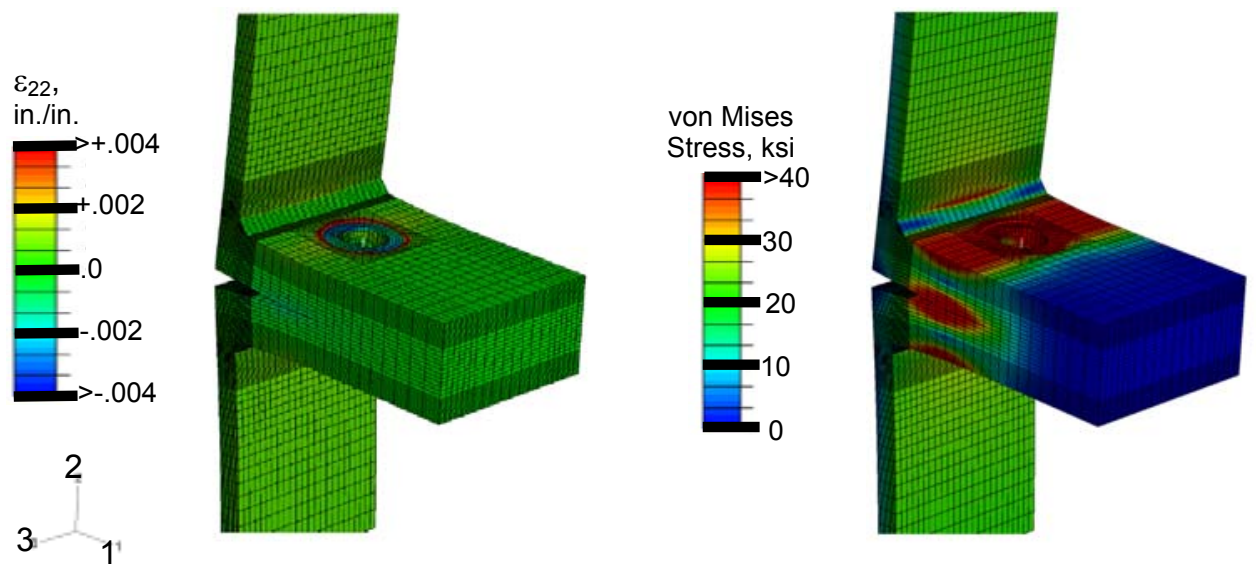

(b) At 30,000 lb (incipient bolt failure load).
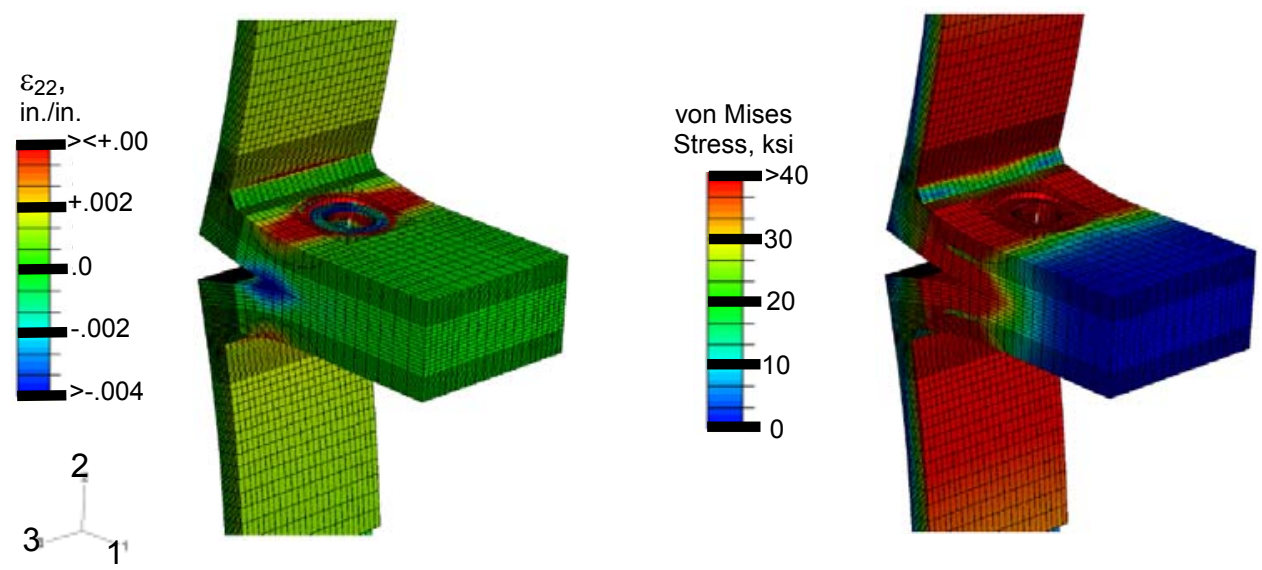

(c) At 38,300 lb (final load level computed).

Figure 16. Axial strain and von Mises stress distributions for different load levels for the baseline analysis case (deformations scaled by 10). 


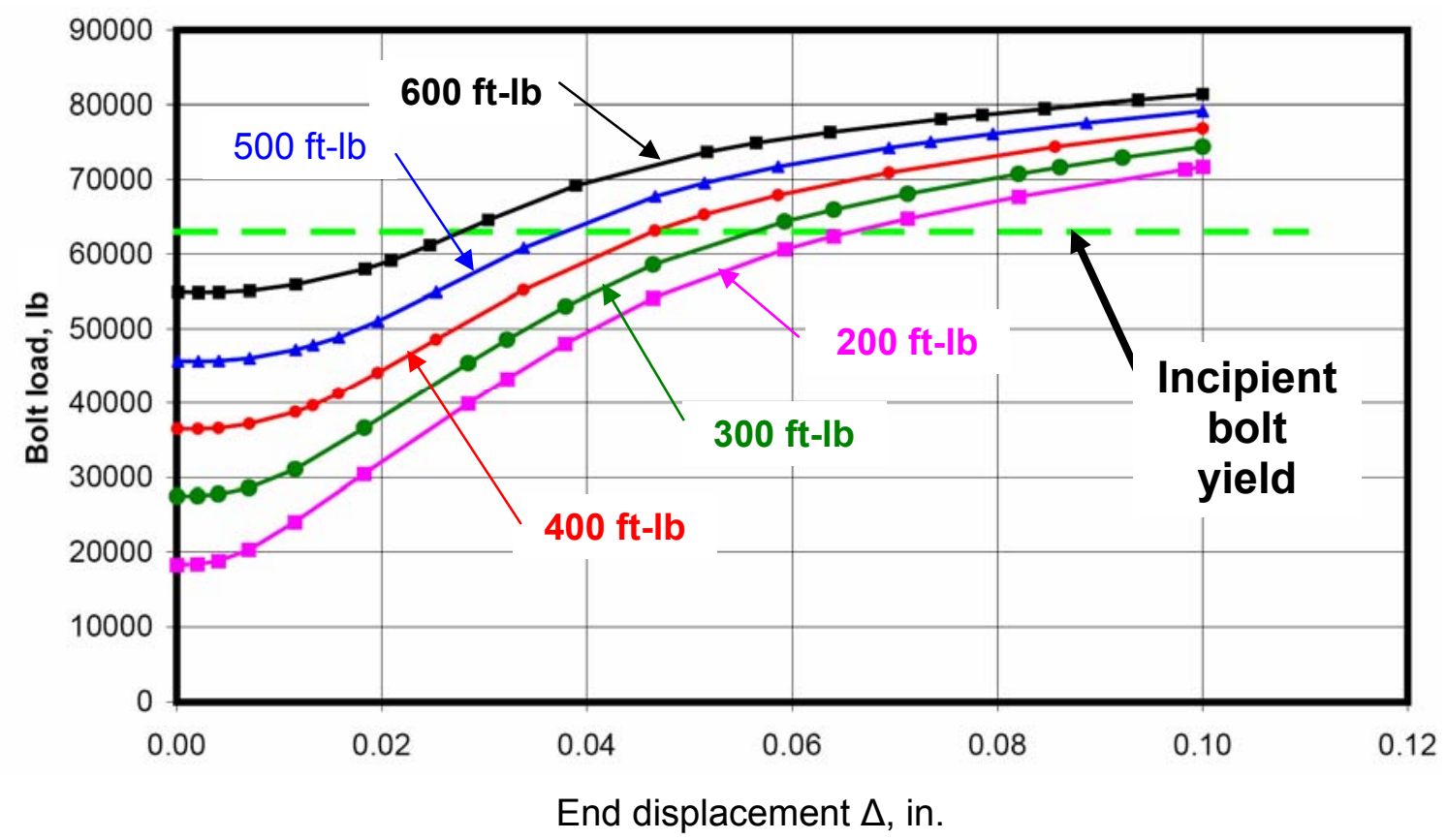

Figure 17. Effect of bolt preload torque on bolt axial load as a function of end displacement.

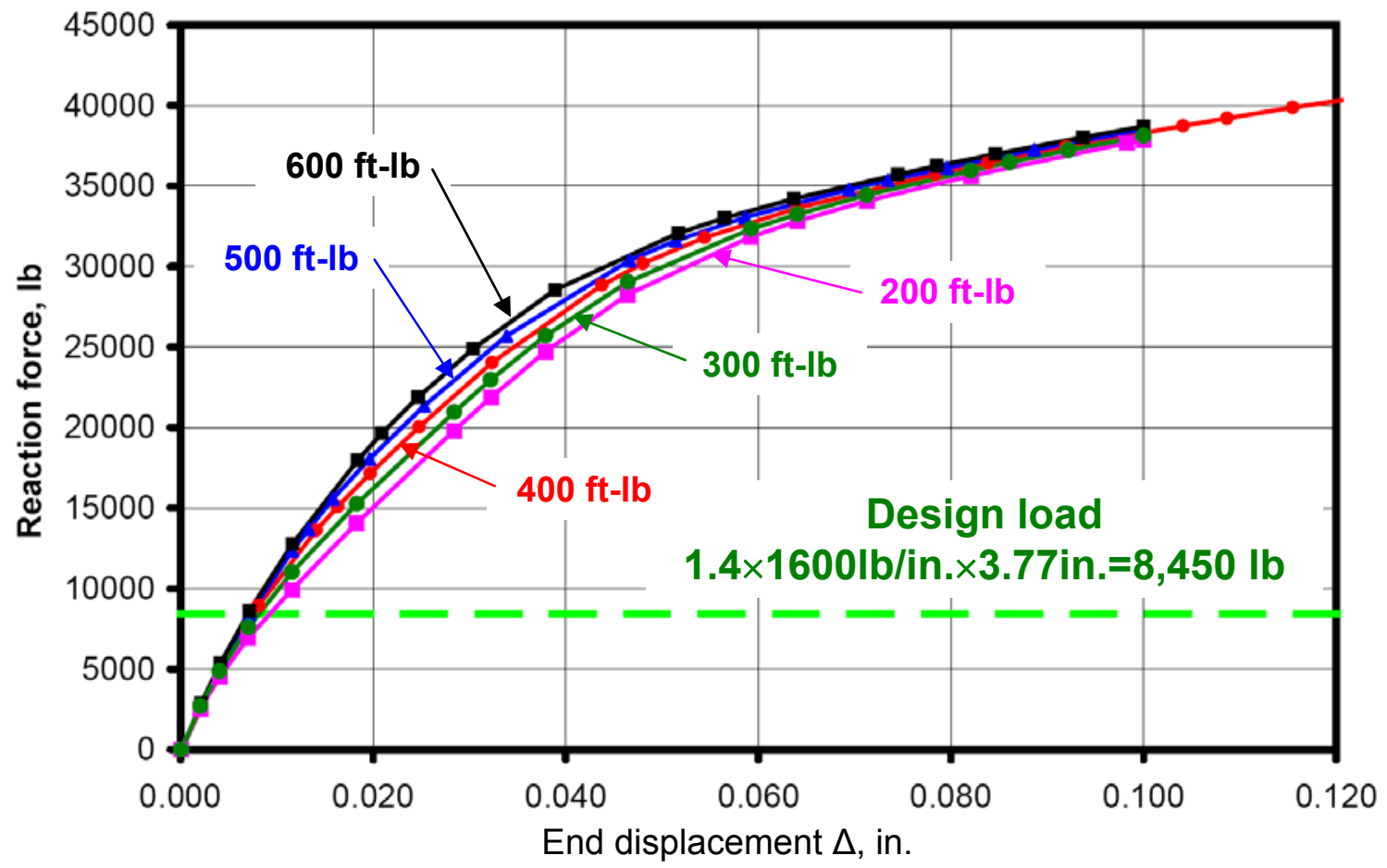

Figure 18. Effect of bolt preload torque on reaction force as a function of end displacement. 


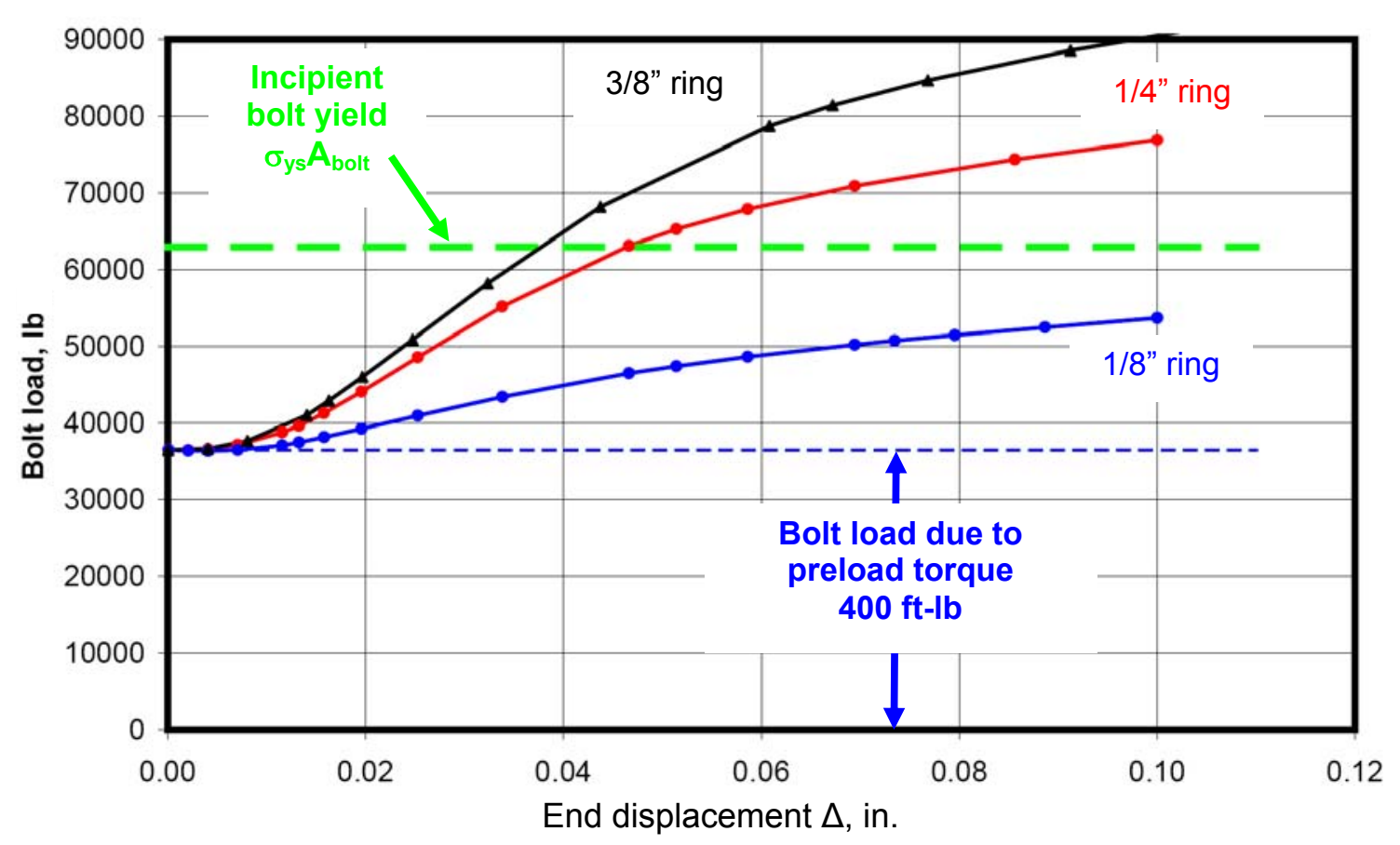

Figure 19. Effect of washer-bearing-surface size on bolt load as a function of end displacement.

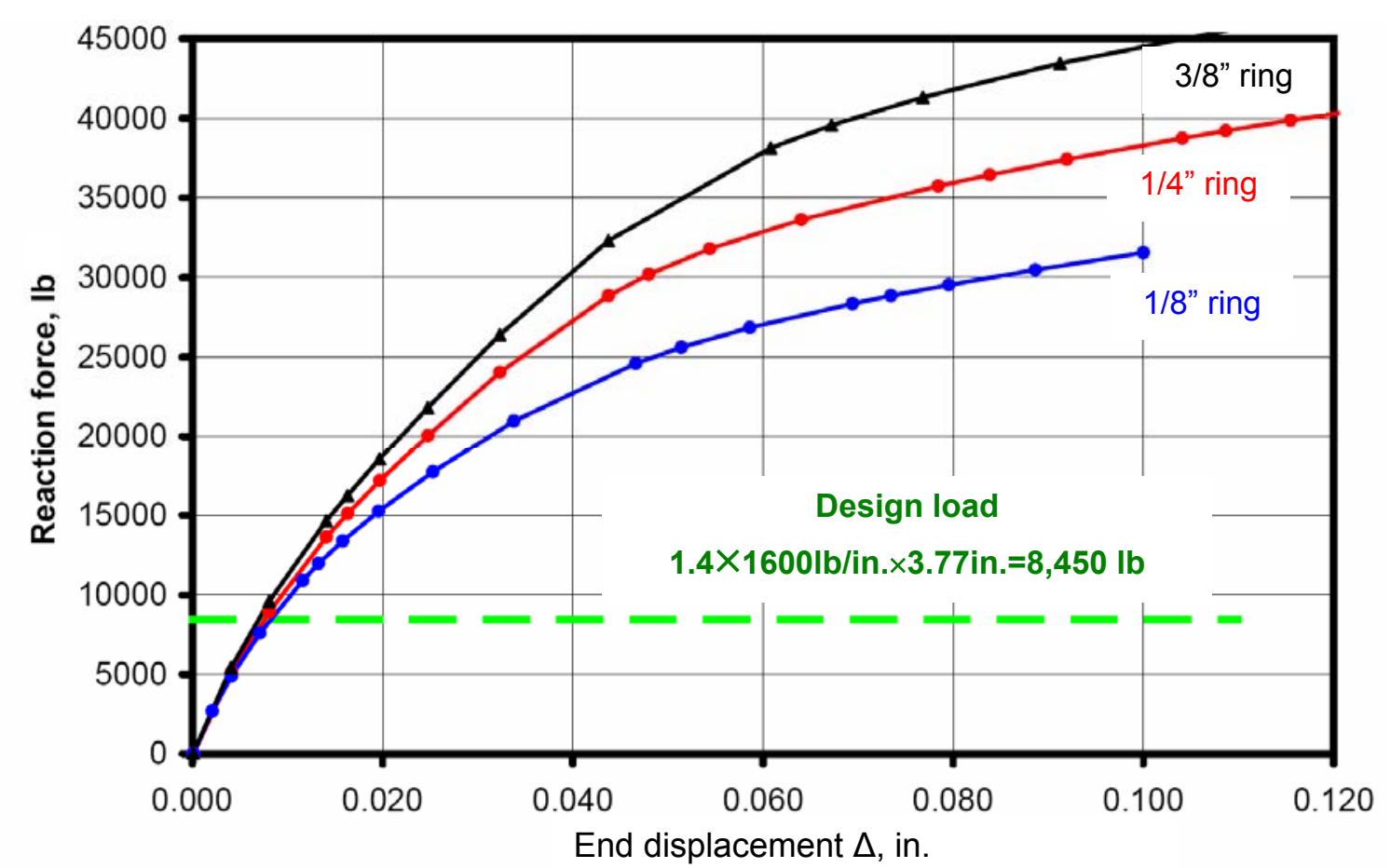

Figure 20. Effect of washer-bearing-surface size on reaction force as a function of end displacement. 


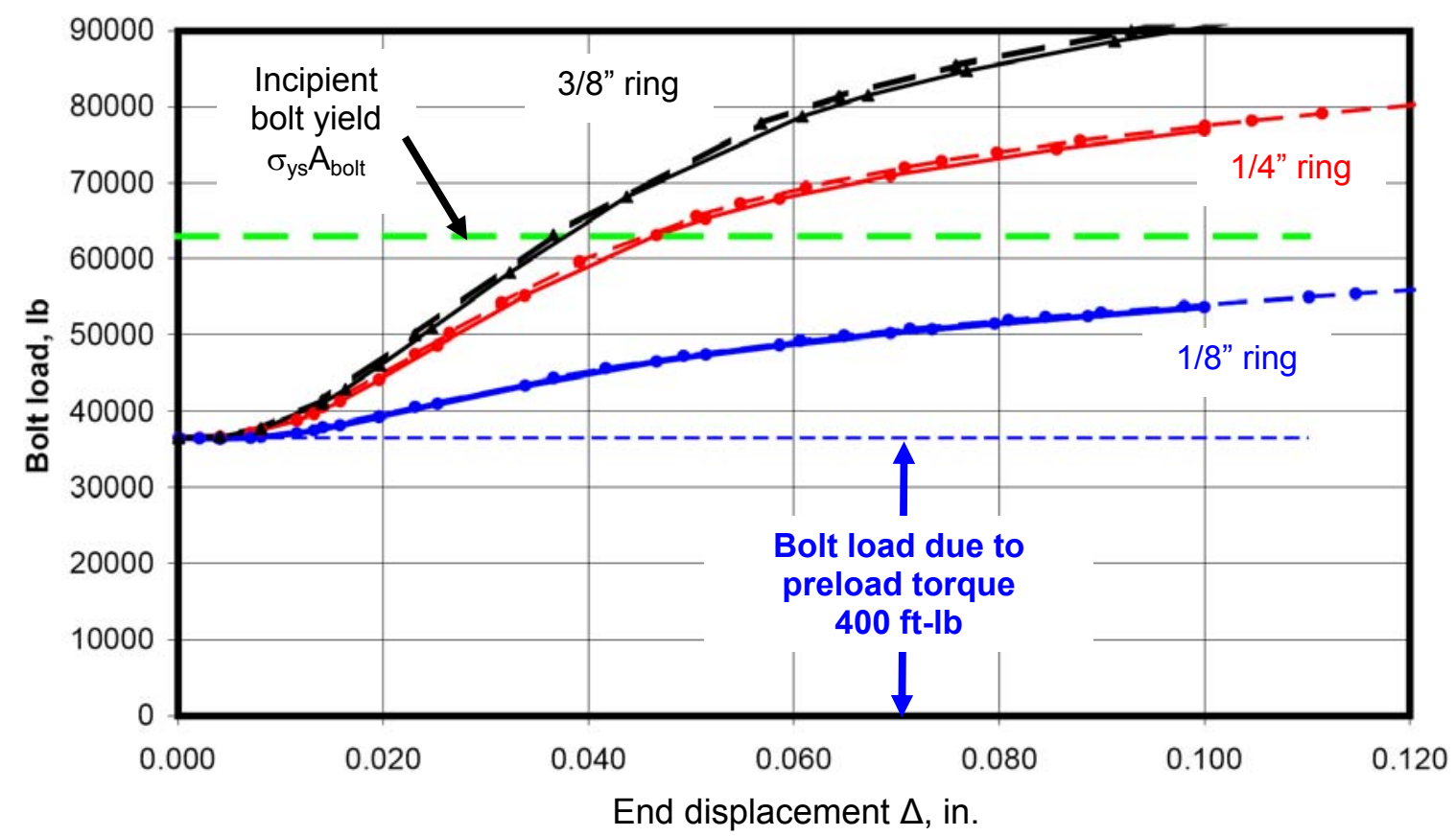

Figure 21. Effect of edge boundary conditions on bolt load as a function of end displacement (solid lines have free long edges; dashed lines have symmetry conditions on long edges).

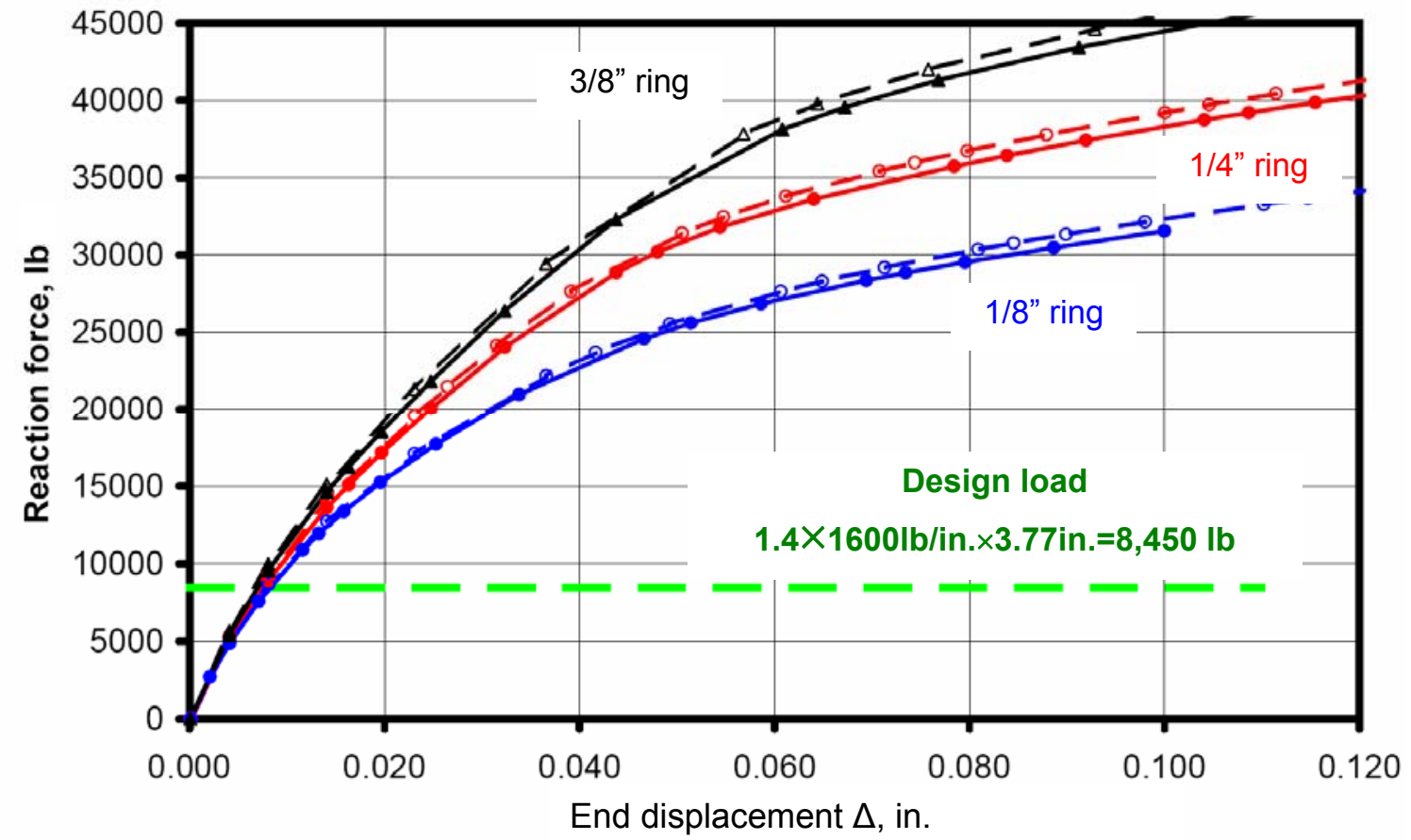

Figure 22. Effect of edge boundary conditions on reaction force as a function of end displacement (solid lines have free long edges; dashed lines have symmetry conditions on long edges). 

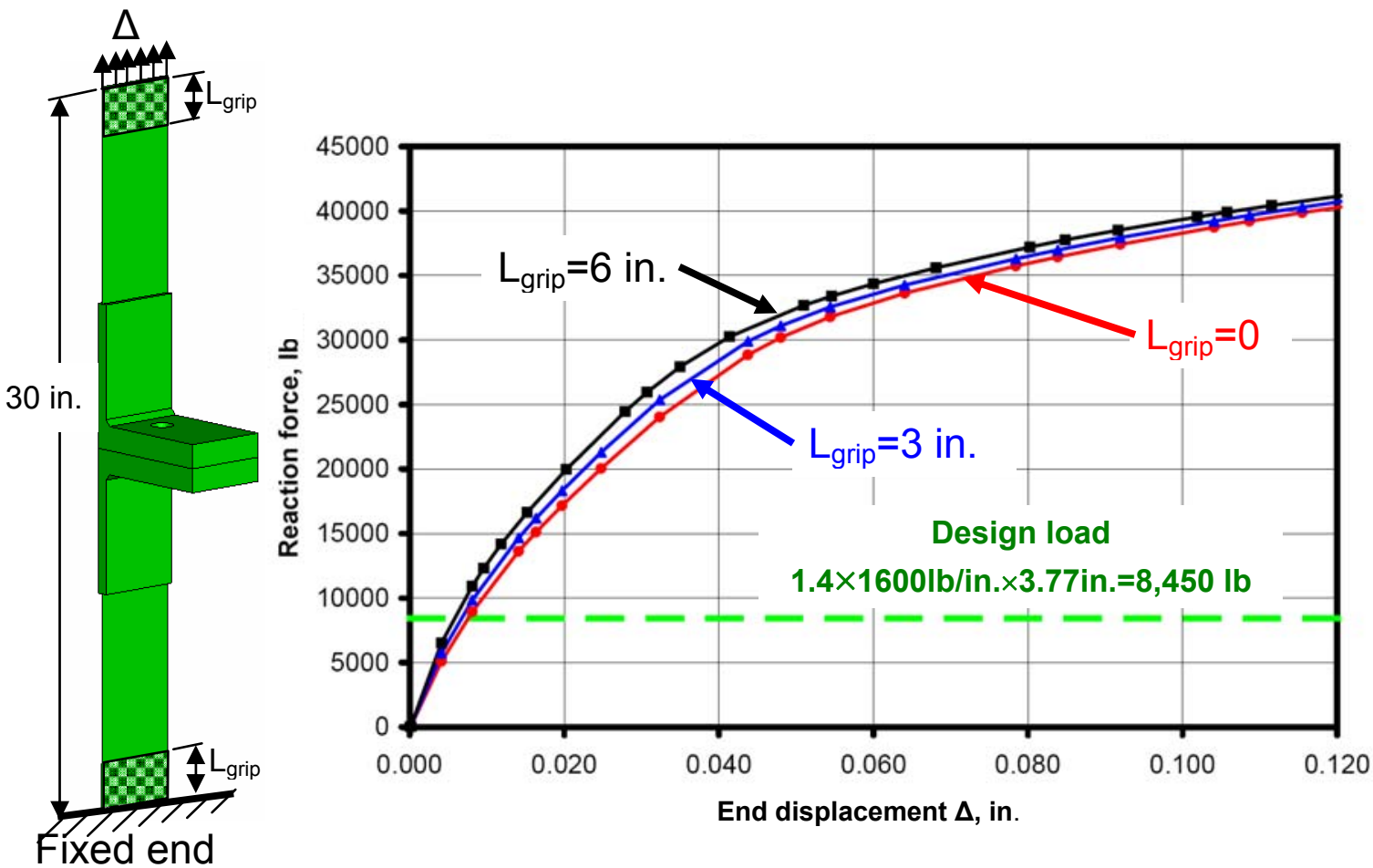

Figure 23. Effect of specimen length on reaction force as a function of end displacement.

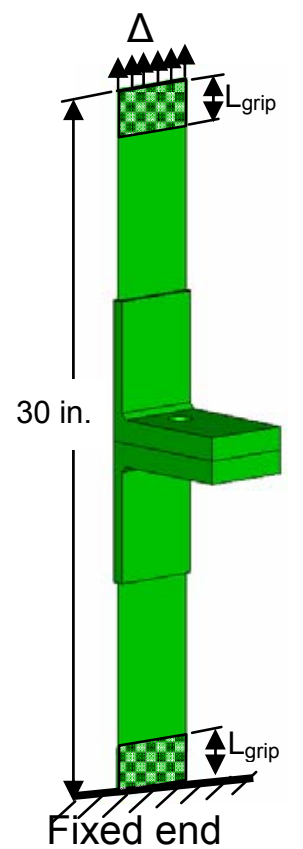

$L_{\text {grip }}=0$

$\mathrm{L}_{\text {grip }}=3$ in.

$L_{\text {grip }}=6$ in.
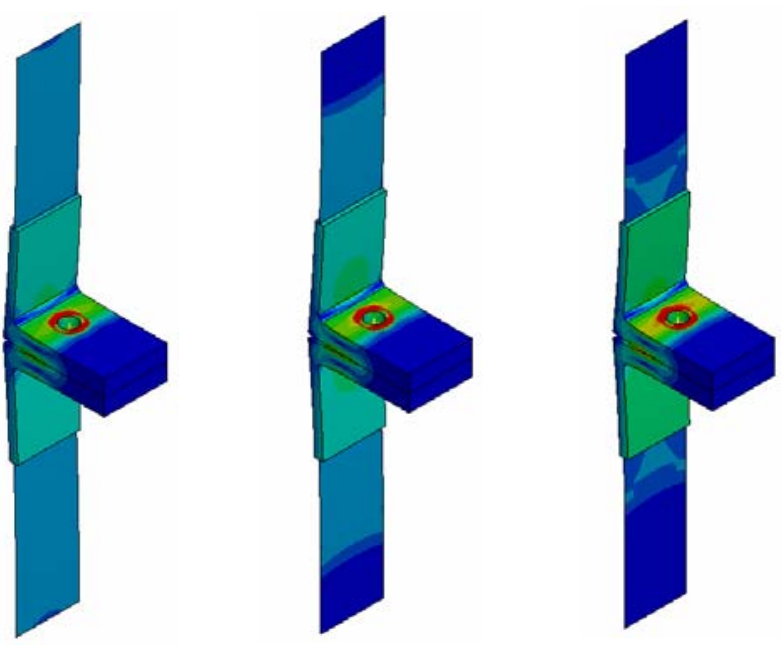

von Mises

Stress

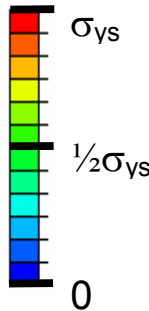

Figure 24. Distribution of von Mises stress for different grip lengths at an end displacement of 0.02 inches. 


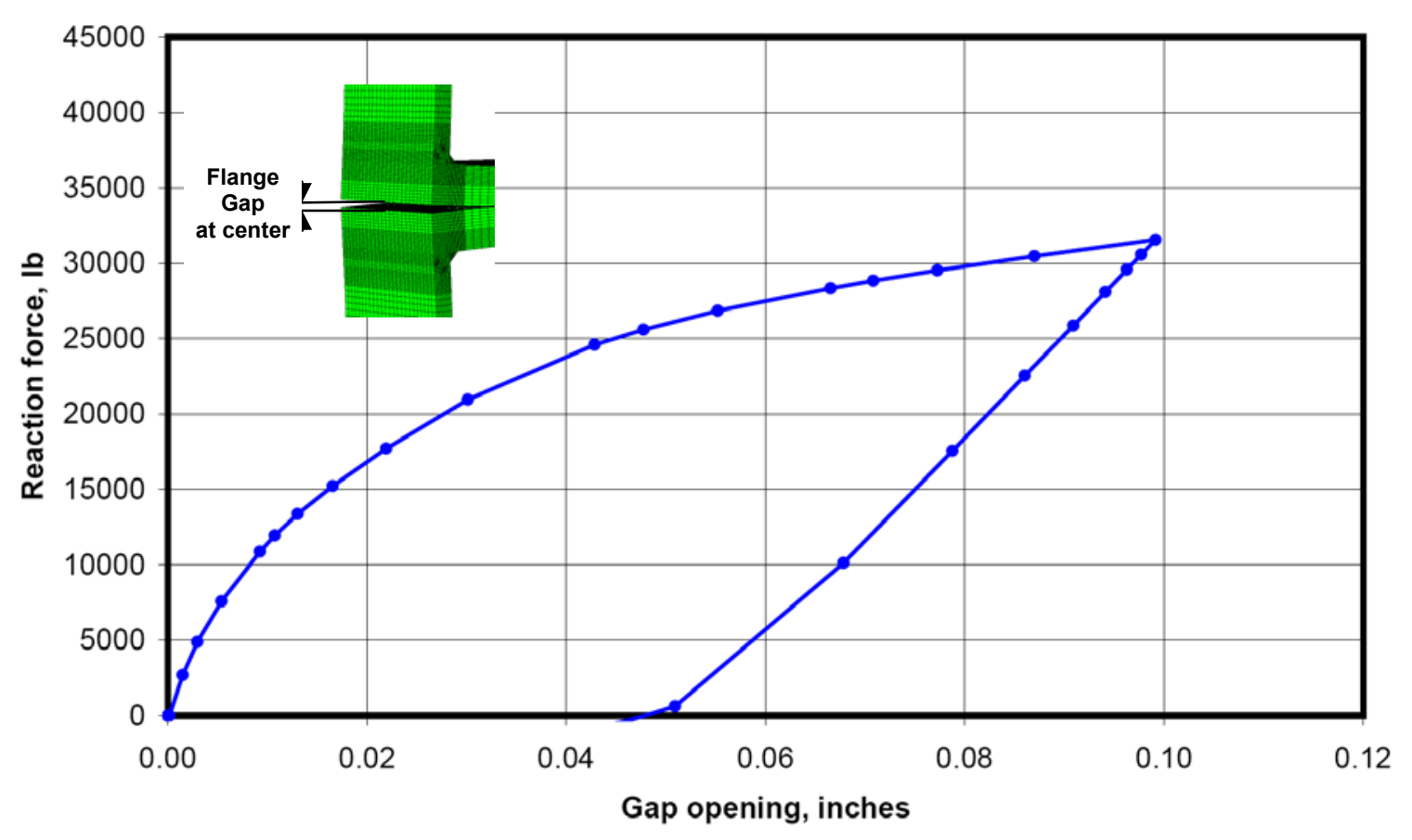

Figure 25. Reaction force as a function of flange separation (gap opening) for the preloaded bolted-joint simulation with $\beta=1 / 8$ inch.

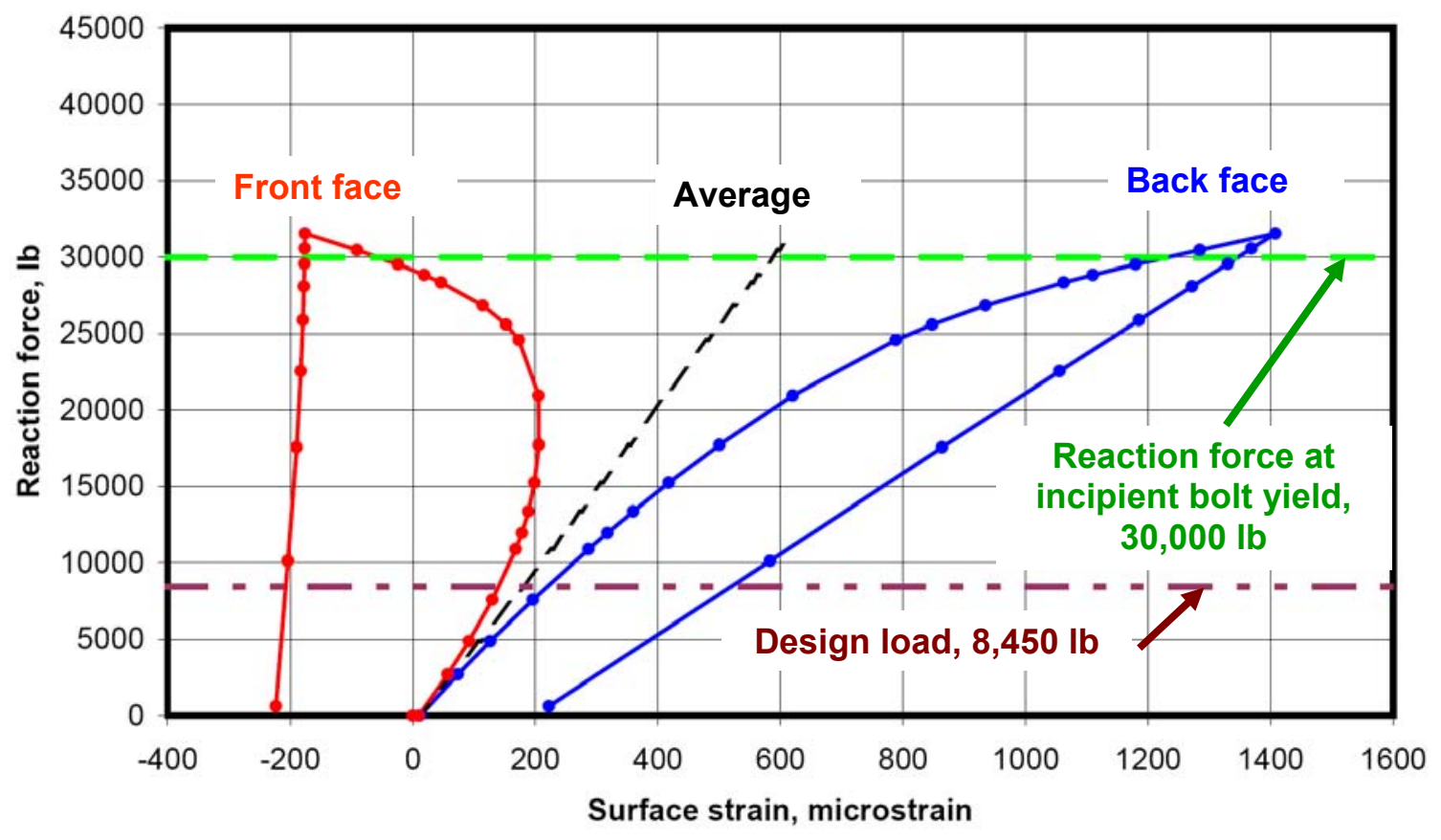

Figure 26. Surface strain response for preloaded bolted-joint simulation with $\beta=1 / 8$ inch. 